Research Article

\title{
Synthesis, Characterization, and In Vitro Cytotoxicity of Platinum(II) Complexes Bearing Chiral Tetradentate Salicylaldimine Ligands
}

\author{
Quang Trung Nguyen ${ }^{10},{ }^{1,2}$ Phuong Nam Pham Thi, ${ }^{1}$ and Van Tuyen Nguyen ${ }^{1,2}$ \\ ${ }^{1}$ Institute of Chemistry, Vietnam Academy of Science and Technology, Hanoi, Vietnam \\ ${ }^{2}$ Graduate School of Science and Technology, 18 Hoang Quoc Viet, Cau Giay, Hanoi, Vietnam \\ Correspondence should be addressed to Quang Trung Nguyen; trungquang_cnhh@yahoo.com
}

Received 23 September 2019; Revised 30 March 2020; Accepted 10 April 2020; Published 16 June 2020

Academic Editor: Michele Benedetti

Copyright (C) 2020 Quang Trung Nguyen et al. This is an open access article distributed under the Creative Commons Attribution License, which permits unrestricted use, distribution, and reproduction in any medium, provided the original work is properly cited.

A series of platinum(II) complexes with chiral Schiff base ligands derived from various salicylaldehydes with $\left(R, R^{\prime}\right)$ - and $\left(S, S^{\prime}\right)$ cyclohexanediamine were synthesized and characterized by ESI-MS, IR, and NMR. Obtained spectra with typical signals were in agreement with suggested molecular formulae of the complexes. Their photophysical properties were studied by UV-visible and emission spectroscopies. The UV-Vis showed the typical band with low energy at visible range 400-500 nm for MLCT, and this band can emit the luminescent band with emission maximum wavelengths at 529-595 $\mathrm{nm}$. The in vitro cytotoxicity of obtained platinum(II) complexes was screened for KB and MCF-7 human cancer cell lines. The results showed that $(S)$-enantiomers were more active than $(R)$-enantiomers and the different positions of methoxy group in salicyl ring gave different cytotoxicities.

\section{Introduction}

Schiff bases are considered as a very important class of organic compounds which have been applied in many biological aspects such as antimicrobial, antifungal, and antitumor activity [1]. Their coordination with transition metals generated a great deal of relatively stable transition metal complexes which have showed interesting properties used in chemical catalysis [2-4], analysis [5-7], and advanced materials [8-10]. These coordination compounds have also exhibited wonderful biological applications including antimicrobial, antifungal, anti-inflammatory, and anticancer activity [11-15]. The medicinal properties of metal Schiff base complexes depend on the nature of metal ions and ligands. One of the life's biochemical features is chirality. Sometimes, chirality plays a decisive role in the area of pharmaceuticals, agrochemicals, flavors, and fragrances. In most cases, all the enantiomers of a chiral compound are considered as different "chemicals" and each stereoisomer is tested separately for its drug action [16]. So, chiral metal complexes have attracted the attention of many research groups. Some chiral Schiff base complexes of $\mathrm{Ni}(\mathrm{II})$, $\mathrm{Cu}(\mathrm{II})$, and $\mathrm{Zn}(\mathrm{II})$ and their DNA binding, antioxidant, and antibacterial activities were studied, and the results showed that $S$-enantiomers of the complexes were more efficient for DNA interaction, antioxidant, and antibacterial activities than their $R$-enantiomers $[17,18]$. Chiral Mn(IV) complexes with Schiff base ligands were synthesized, and the interaction of the chiral Mn(IV) complexes with CT-DNA was studied, and the results showed that the complexes with $(S)$-ligands exhibited more efficient CT-DNA interaction than the complexes with $(R)$-ligands [19]. Recently, there were some studies on bioactivity of tetradentate salicylaldimine platinum(II) complexes [20-23]; however, the research number of chiral Schiff base platinum(II) complexes in this field is quite limited. In this work, we continue to study on the synthesis of a series of platinum(II) complexes with chiral tetradentate salicylaldimine ligands obtained by the reaction of $\left(R, R^{\prime}\right)$-cyclohexanediamine and $\left(S, S^{\prime}\right)$-cyclohexanediamine with some salicylaldehydes. Characterization of 
obtained complexes was studied by ESI-MS, FT-IR, NMR, and CD spectroscopies, and their photophysical properties were studied by UV-Vis and luminescent spectra. Their in vitro antitumor activities are also evaluated against $\mathrm{KB}$ and MCF-7 human cancer cell lines.

\section{Materials and Methods}

Analytical reagent grade chemicals were used as received from commercial companies without further purification. All solvents were purified by following the appropriate purification procedures.

Mass spectra $(\mathrm{m} / \mathrm{z})$ were recorded on Agilent 6310 Ion Trap spectrometer. Infrared spectra $\left(\mathrm{cm}^{-1}\right)$ were obtained from $\mathrm{KBr}$ pellets using a Perkin Elmer Spectrum Two spectrophotometer. ${ }^{1} \mathrm{H}-\mathrm{NMR}$ and ${ }^{13} \mathrm{C}-\mathrm{NMR}$ spectra were analyzed using a Bruker Advance $500 \mathrm{MHz}$ NMR spectrometer with TMS as internal standard, and chemical shifts $(\delta)$ were recorded in ppm. Optical rotations were recorded on Atago POLAX-2L polarimeter at the wavelength of measuring light $589 \mathrm{~nm}$ for studied ligands. CD spectra (235-400 nm) were measured on a Chirascan CD spectrometer for obtained chiral salen platinum(II) complexes.

\section{Preparation of Chiral Schiff Base Ligands}

Chiral Schiff base ligands were prepared similarly according to the known procedure from the condensation of $\left(R, R^{\prime}\right)$ - or $\left(S, S^{\prime}\right)$-cyclohexanediamine with the relative salicylaldehydes [24]. Pure $(R, R)$-1,2-diaminonium cyclohexane mono-L$(+)$-tartrate or $(S, S)$-1,2-diaminonium cyclohexane monoD-(+)-tartrate $(2.05 \mathrm{~g}, 7.6 \mathrm{mmol})$ and $\mathrm{Na}_{2} \mathrm{CO}_{3}$ (1.65 g, $15.5 \mathrm{mmol})$ with added methylene chloride $(20 \mathrm{~mL})$ and distilled water $(15 \mathrm{~mL})$ in a $100 \mathrm{ml}$ flask were stirred for $1 \mathrm{~h}$. After the mixture turned to clear solutions, relative salicylaldehyde $(15.4 \mathrm{mmol})$ was added to organic layer and the new mixture was put under ultrasound for $1 \mathrm{~h}$ and then separated to dryness. The organic layer was dried over anhydrous $\mathrm{Na}_{2} \mathrm{SO}_{4}$, and the solvent was removed under reduced pressure to obtain a yellowish product.

3.1. $N, N^{\prime}$-Bisalicylidene- $\left(R, R^{\prime}\right)-1,2$-cyclohexanediamine $((R)$ $\left.\mathrm{L}_{1} \mathrm{H}_{2}\right)$. Yellow oil product (92\%), ESI-MS (m/z) 323.0 $\left(\mathrm{M}+\mathrm{H}^{+}\right),[\boldsymbol{\alpha}]_{\mathbf{D}}-79\left(\right.$ c $\left.1.1 ; \mathrm{CHCl}_{3}\right) . \mathbf{I R}\left(\mathrm{KBr}, \mathrm{cm}^{-1}\right): 2933(\nu$, $\mathrm{C}-\mathrm{H}), 2647$ ( $\nu, \mathrm{O}-\mathrm{H}), 1630(\nu, \mathrm{C}=\mathrm{N}), 1497(\nu, \mathrm{C}=\mathrm{C}), 1278$ $(\nu, \mathrm{C}-\mathrm{N}), 1204(\nu, \mathrm{C}-\mathrm{O}), 848,755(\delta, \mathrm{C}-\mathrm{H}), 663 .{ }^{\mathbf{1}} \mathbf{H}-\mathbf{N M R}$ $\left(\mathrm{CDCl}_{3}, 500 \mathrm{MHz}, \mathrm{ppm}\right): \delta 13.29$ (s, 2H, 2OH), $8.24(\mathrm{~s}, 2 \mathrm{H}$, $2 \mathrm{CH}=\mathrm{N}), 7.22(\mathrm{dt}, J=8.5 ; 1.5,2 \mathrm{H}, \mathrm{ArH}), 7.13(\mathrm{dd}, J=7.5 ; 1.5$, $2 \mathrm{H}, \operatorname{ArH}), 6.87(\mathrm{~d}, J=8.0,2 \mathrm{H}, \operatorname{ArH}), 6.78(\mathrm{t}, J=7.5,2 \mathrm{H}$, ArH), 3.29 (m, 2H, CyH), $1.93(\mathrm{~m}, 2 \mathrm{H}, \mathrm{CyH}), 1.86(\mathrm{~m}, 2 \mathrm{H}$, $\mathrm{CyH}), 1.72(\mathrm{~m}, 2 \mathrm{H}, \mathrm{CyH}), 1.46$ (m, 2H, CyH). ${ }^{13} \mathrm{C}-\mathbf{N M R}$ $\left(\mathrm{CDCl}_{3}, 125 \mathrm{MHz}, \mathrm{ppm}\right): \delta 164.72(2 \mathrm{C}, \mathrm{C}-\mathrm{OH}), 160.99(2 \mathrm{C}$, $\mathrm{C}=\mathrm{N}), 132.16\left(2 \mathrm{C}, \mathrm{C}_{\mathrm{Ar}}\right), 131.48\left(2 \mathrm{C}, \mathrm{C}_{\mathrm{Ar}}\right), 118.67\left(2 \mathrm{C}, \mathrm{C}_{\mathrm{Ar}}\right)$, $118.60\left(2 \mathrm{C}, \mathrm{C}_{\mathrm{Ar}}\right), 116.78\left(2 \mathrm{C}, \mathrm{C}_{\mathrm{Ar}}\right), 72.62\left(2 \mathrm{C}, \mathrm{C}_{\mathrm{Cy}}\right), 33.10$ $\left(2 \mathrm{C}, \mathrm{C}_{\mathrm{Cy}}\right), 24.18\left(2 \mathrm{C}, \mathrm{C}_{\mathrm{Cy}}\right)$.

3.2. $N, N^{\prime}$-Bisalicylidene-(S, $\left.S^{\prime}\right)-1,2$-cyclohexanediamine ((S) $\mathrm{L}_{1} \mathrm{H}_{2}$ ). Yellow oil product (91\%), ESI-MS (m/z) 323.0
$\left(\mathrm{M}+\mathrm{H}^{+}\right),[\boldsymbol{\alpha}]_{\mathbf{D}}+78\left(\right.$ c $\left.1.1 ; \mathrm{CHCl}_{3}\right) . \mathbf{I R}\left(\mathrm{KBr}, \mathrm{cm}^{-1}\right): 2932(\nu$, $\mathrm{C}-\mathrm{H}), 2646(\nu, \mathrm{O}-\mathrm{H}), 1630(\nu, \mathrm{C}=\mathrm{N}), 1497(\nu, \mathrm{C}=\mathrm{C}), 1278$ $(\nu, \mathrm{C}-\mathrm{N}), 1204(\nu, \mathrm{C}-\mathrm{O}), 848,755(\delta, \mathrm{C}-\mathrm{H}), 663 .{ }^{\mathbf{1}} \mathbf{H}-\mathbf{N M R}$ $\left(\mathrm{CDCl}_{3}, 500 \mathrm{MHz}, \mathrm{ppm}\right): \delta 13.30(\mathrm{~s}, 2 \mathrm{H}, 2 \mathrm{OH}), 8.25$ (s, $2 \mathrm{H}$, $2 \mathrm{CH}=\mathrm{N}), 7.23(\mathrm{dt}, J=8.5 ; 1.5,2 \mathrm{H}, \operatorname{ArH}), 7.13(\mathrm{dd}, J=7.5 ; 1.5$, $2 \mathrm{H}, \mathrm{ArH}), 6.87(\mathrm{~d}, J=8.5,2 \mathrm{H}, \mathrm{ArH}), 6.78(\mathrm{t}, J=7.5,2 \mathrm{H}$, $\mathrm{ArH}), 3.30$ (m, 2H, CyH), 1.94 (m, 2H, CyH), 1.87 (m, 2H, CyH), 1.73 (m, 2H, CyH), 1.47 (m, 2H, CyH). ${ }^{13} \mathrm{C}-\mathbf{N M R}$ $\left(\mathrm{CDCl}_{3}, 125 \mathrm{MHz}, \mathrm{ppm}\right): \delta 164.72(2 \mathrm{C}, \mathrm{C}-\mathrm{OH}), 160.98(2 \mathrm{C}$, $\mathrm{C}=\mathrm{N}), 132.16\left(2 \mathrm{C}, \mathrm{C}_{\mathrm{Ar}}\right), 131.48\left(2 \mathrm{C}, \mathrm{C}_{\mathrm{Ar}}\right), 118.67\left(2 \mathrm{C}, \mathrm{C}_{\mathrm{Ar}}\right)$, $118.59\left(2 \mathrm{C}, \mathrm{C}_{\mathrm{Ar}}\right), 116.77\left(2 \mathrm{C}, \mathrm{C}_{\mathrm{Ar}}\right), 72.63\left(2 \mathrm{C}, \mathrm{C}_{\mathrm{Cy}}\right), 33.10$ $\left(2 \mathrm{C}, \mathrm{C}_{\mathrm{Cy}}\right), 24.18\left(2 \mathrm{C}, \mathrm{C}_{\mathrm{Cy}}\right)$.

3.3. $N, N^{\prime}$-Bis(5-fluorosalicylidene)-(R, $\left.R^{\prime}\right)$-1,2-cyclohexanediamine $\left((\mathrm{R}) \mathrm{L}_{2} \mathrm{H}_{2}\right)$. Yellow solid product $(93 \%), \mathbf{E S I}-\mathbf{M S}(\mathrm{m} / \mathrm{z})$ $359.0\left(\mathrm{M}+\mathrm{H}^{+}\right),[\boldsymbol{\alpha}]_{\mathbf{D}}-50\left(\right.$ c $\left.1.0 ; \mathrm{CHCl}_{3}\right)$. IR $\left(\mathrm{KBr}, \mathrm{cm}^{-1}\right)$ : $2920(\nu, \mathrm{C}-\mathrm{H}), 2603(\nu, \mathrm{O}-\mathrm{H}), 1635(\nu, \mathrm{C}=\mathrm{N}), 1488(\nu$, $\mathrm{C}=\mathrm{C}), 1273(\nu, \mathrm{C}-\mathrm{N}), 1196(\nu, \mathrm{C}-\mathrm{O}), 1140,825,784(\delta$, $\mathrm{C}-\mathrm{H}), 677 .{ }^{1} \mathrm{H}-\mathbf{N M R}\left(\mathrm{CDCl}_{3}, 500 \mathrm{MHz}, \mathrm{ppm}\right): \delta 12.94(\mathrm{~s}$, $2 \mathrm{H}, 2 \mathrm{OH}), 8.19(\mathrm{~s}, 2 \mathrm{H}, 2 \mathrm{CH}=\mathrm{N}), 6.96(\mathrm{dt}, J=9.0 ; 3.0,2 \mathrm{H}$, ArH), 6.84 (m, 4H, ArH), 3.32 (m, 2H, CyH), 1.94 (m, 2H, CyH), 1.89 (m, 2H, CyH), 1.72 (m, 2H, CyH), 1.48 (m, 2H, $\mathrm{CyH}) .{ }^{13} \mathrm{C}-\mathrm{NMR}\left(\mathrm{CDCl}_{3}, 125 \mathrm{MHz}, \mathrm{ppm}\right): \delta 163.73$ and 163.71 (2C, C-OH), 156.98 and 156.27 (2C, C-F), 154.39 $(2 \mathrm{C}, \mathrm{C}=\mathrm{N}), 119.38$ and $119.19\left(2 \mathrm{C}, \mathrm{C}_{\mathrm{Ar}}\right), 118.32$ and 118.26 $\left(2 \mathrm{C}, \mathrm{C}_{\mathrm{Ar}}\right), 117.85$ and $117.79\left(2 \mathrm{C}, \mathrm{C}_{\mathrm{Ar}}\right), 116.61$ and 116.43 $\left(2 \mathrm{C}, \mathrm{C}_{\mathrm{Ar}}\right), 72.68\left(2 \mathrm{C}, \mathrm{C}_{\mathrm{Cy}}\right), 32.94\left(2 \mathrm{C}, \mathrm{C}_{\mathrm{Cy}}\right), 24.09\left(2 \mathrm{C}, \mathrm{C}_{\mathrm{Cy}}\right)$.

3.4. $N, N^{\prime}$-Bis(5-fluorosalicylidene)-(S, $\left.S^{\prime}\right)$-1,2-cyclohexanediamine $\left((\mathrm{S}) \mathrm{L}_{2} \mathrm{H}_{2}\right)$. Yellow solid product $(94 \%)$, ESI-MS $(\mathrm{m} / \mathrm{z})$ $359.0\left(\mathrm{M}+\mathrm{H}^{+}\right),[\boldsymbol{\alpha}]_{\mathbf{D}}+50\left(\right.$ c $\left.1.0 ; \mathrm{CHCl}_{3}\right)$. IR $\left(\mathrm{KBr}, \mathrm{cm}^{-1}\right)$ : $2920(\nu, \mathrm{C}-\mathrm{H}), 2602(\nu, \mathrm{O}-\mathrm{H}), 1634(\nu, \mathrm{C}=\mathrm{N}), 1486(\nu$, $\mathrm{C}=\mathrm{C}), 1273(\nu, \mathrm{C}-\mathrm{N}), 1196(\nu, \mathrm{C}-\mathrm{O}), 1140,824,784(\delta$, $\mathrm{C}-\mathrm{H}), 676 ;{ }^{1} \mathrm{H}-\mathbf{N M R}\left(\mathrm{CDCl}_{3}, 500 \mathrm{MHz}, \mathrm{ppm}\right): \delta 12.93(\mathrm{~s}$, $2 \mathrm{H}, 2 \mathrm{OH}), 8.19(\mathrm{~s}, 2 \mathrm{H}, 2 \mathrm{CH}=\mathrm{N}), 6.96(\mathrm{dt}, J=9.0 ; 3.0,2 \mathrm{H}$, ArH), 6.84 (m, 4H, ArH), 3.32 (m, 2H, CyH), 1.95 (m, 2H, CyH), 1.89 (m, 2H, CyH), 1.72 (m, 2H, CyH), 1.48 (m, 2H, $\mathrm{CyH}) ;{ }^{13} \mathrm{C}-\mathrm{NMR}\left(\mathrm{CDCl}_{3}, 125 \mathrm{MHz}, \mathrm{ppm}\right): \delta 163.73$ and 163.71 (2C, C-OH), 157.00 and 156.29 (2C, C-F), 154.41 $(2 \mathrm{C}, \mathrm{C}=\mathrm{N}), 119.38$ and $119.20\left(2 \mathrm{C}, \mathrm{C}_{\mathrm{Ar}}\right), 118.33$ and 118.27 $\left(2 \mathrm{C}, \mathrm{C}_{\mathrm{Ar}}\right), 117.86$ and $117.80\left(2 \mathrm{C}, \mathrm{C}_{\mathrm{Ar}}\right), 116.61$ and 116.42 $\left(2 \mathrm{C}, \mathrm{C}_{\mathrm{Ar}}\right), 72.69\left(2 \mathrm{C}, \mathrm{C}_{\mathrm{Cy}}\right), 32.95\left(2 \mathrm{C}, \mathrm{C}_{\mathrm{Cy}}\right), 24.10\left(2 \mathrm{C}, \mathrm{C}_{\mathrm{Cy}}\right)$.

3.5. $N, N^{\prime}$-Bis(3-methoxysalicylidene)-(R, $\left.R^{\prime}\right)-1,2$-cyclohexanediamine $\left((\mathrm{R}) \mathrm{L}_{3} \mathrm{H}_{2}\right)$. Yellow oil product $(90 \%)$, ESI-MS $(\mathrm{m} / \mathrm{z})$ $383.0\left(\mathrm{M}+\mathrm{H}^{+}\right),[\boldsymbol{\alpha}]_{\mathbf{D}}-60\left(\right.$ c $\left.1.0 ; \mathrm{CHCl}_{3}\right)$. IR $\left(\mathrm{KBr}, \mathrm{cm}^{-1}\right)$ : $2933(\nu, \mathrm{C}-\mathrm{H}), 2667(\nu, \mathrm{O}-\mathrm{H}), 1627(\nu, \mathrm{C}=\mathrm{N}), 1465(\nu$, $\mathrm{C}=\mathrm{C}), 1251(\nu, \mathrm{C}-\mathrm{N}), 1169(\nu, \mathrm{C}-\mathrm{O}), 1083,839,735(\delta$, $\mathrm{C}-\mathrm{H}), 647 .{ }^{\mathbf{1}} \mathrm{H}-\mathrm{NMR}\left(\mathrm{CDCl}_{3}, 500 \mathrm{MHz}, \mathrm{ppm}\right): \delta 13.82(\mathrm{~s}$, $2 \mathrm{H}, 2 \mathrm{OH}), 8.24(\mathrm{~s}, 2 \mathrm{H}, 2 \mathrm{CH}=\mathrm{N}), 6.85(\mathrm{dd}, J=8.0 ; 1.5,2 \mathrm{H}$, ArH), 6.78 (dd, $J=8.0 ; 1.5,2 \mathrm{H}, \mathrm{ArH}), 6.72(\mathrm{t}, J=8.0,2 \mathrm{H}$, $\mathrm{ArH}), 3.86$ (s, 6H, 2 MeO), 3.31 (m, 2H, CyH), 1.94 (m, 2H, $\mathrm{CyH}), 1.87$ (m, 2H, CyH), 1.72 (m, 2H, CyH), 1.48 (m, 2H, $\mathrm{CyH}) .{ }^{13} \mathrm{C}-\mathrm{NMR}\left(\mathrm{CDCl}_{3}, 125 \mathrm{MHz}, \mathrm{ppm}\right): \delta 164.75(2 \mathrm{C}$, $\mathrm{C}-\mathrm{OH}), 151.62(2 \mathrm{C}, \mathrm{C}=\mathrm{N}), 148.26$ (2C, C-OMe), 123.19 $\left(2 \mathrm{C}, \mathrm{C}_{\mathrm{Ar}}\right), 118.41\left(2 \mathrm{C}, \mathrm{C}_{\mathrm{Ar}}\right), 117.87\left(2 \mathrm{C}, \mathrm{C}_{\mathrm{Ar}}\right), 113.92(2 \mathrm{C}$, 
$\left.\mathrm{C}_{\mathrm{Ar}}\right), 72.41\left(2 \mathrm{C}, \mathrm{C}_{\mathrm{Cy}}\right), 56.04(2 \mathrm{C}, \mathrm{MeO}), 33.02\left(2 \mathrm{C}, \mathrm{C}_{\mathrm{Cy}}\right)$, $24.05\left(2 \mathrm{C}, \mathrm{C}_{\mathrm{Cy}}\right)$.

3.6. $N, N^{\prime}$-Bis(3-methoxysalicylidene)-(S,S $)$-1,2-cyclohexanediamine $\left((\mathrm{S}) \mathrm{L}_{3} \mathrm{H}_{2}\right)$. Yellow oil product $(91 \%), \mathbf{E S I}-\mathbf{M S}(\mathrm{m} / \mathrm{z})$ $383.0\left(\mathrm{M}+\mathrm{H}^{+}\right),[\boldsymbol{\alpha}]_{\mathbf{D}}+59\left(\right.$ c 1.0; $\left.\mathrm{CHCl}_{3}\right)$. IR $\left(\mathrm{KBr}, \mathrm{cm}^{-1}\right)$ : $2926(\nu, \mathrm{C}-\mathrm{H}), 2665(\nu, \mathrm{O}-\mathrm{H}), 1625(\nu, \mathrm{C}=\mathrm{N}), 1461(\nu, \mathrm{C}=\mathrm{C})$, $1248(\nu, \mathrm{C}-\mathrm{N}), 1169(\nu, \mathrm{C}-\mathrm{O}), 1080,838,731(\delta, \mathrm{C}-\mathrm{H}), 646$. ${ }^{1} \mathrm{H}-\mathrm{NMR}\left(\mathrm{CDCl}_{3}, 500 \mathrm{MHz}, \mathrm{ppm}\right): \delta 13.82(\mathrm{~s}, 2 \mathrm{H}, 2 \mathrm{OH})$, $8.24(\mathrm{~s}, 2 \mathrm{H}, 2 \mathrm{CH}=\mathrm{N}), 6.85(\mathrm{~d}, J=8.0,2 \mathrm{H}, \operatorname{ArH}), 6.78(\mathrm{~d}$, $J=7.0,2 \mathrm{H}, \mathrm{ArH}), 6.72(\mathrm{t}, J=8.0,2 \mathrm{H}, \mathrm{ArH}), 3.86(\mathrm{~s}, 6 \mathrm{H}, 2$ $\mathrm{MeO}), 3.31(\mathrm{~m}, 2 \mathrm{H}, \mathrm{CyH}), 1.94(\mathrm{~m}, 2 \mathrm{H}, \mathrm{CyH}), 1.87(\mathrm{~m}, 2 \mathrm{H}$, $\mathrm{CyH}), 1.72(\mathrm{~m}, 2 \mathrm{H}, \mathrm{CyH}), 1.48(\mathrm{~m}, 2 \mathrm{H}, \mathrm{CyH}) .{ }^{13} \mathrm{C}-\mathbf{N M R}$ $\left(\mathrm{CDCl}_{3}, 125 \mathrm{MHz}, \mathrm{ppm}\right): \delta 164.75(2 \mathrm{C}, \mathrm{C}-\mathrm{OH}), 151.61$ (2C, $\mathrm{C}=\mathrm{N}), 148.26(2 \mathrm{C}, \mathrm{C}-\mathrm{OMe}), 123.19\left(2 \mathrm{C}, \mathrm{C}_{\mathrm{Ar}}\right), 118.42(2 \mathrm{C}$, $\left.\mathrm{C}_{\mathrm{Ar}}\right), 117.87\left(2 \mathrm{C}, \mathrm{C}_{\mathrm{Ar}}\right), 113.92\left(2 \mathrm{C}, \mathrm{C}_{\mathrm{Ar}}\right), 72.41\left(2 \mathrm{C}, \mathrm{C}_{\mathrm{Cy}}\right)$, $56.04(2 \mathrm{C}, \mathrm{MeO}), 33.02\left(2 \mathrm{C}, \mathrm{C}_{\mathrm{Cy}}\right), 24.05\left(2 \mathrm{C}, \mathrm{C}_{\mathrm{Cy}}\right)$.

3.7. $N, N^{\prime}$-Bis(4-methoxysalicylidene)-( $\left.R, R^{\prime}\right)-1,2$-cyclohexanediamine $\left((\mathrm{R}) \mathrm{L}_{4} \mathrm{H}_{2}\right)$. Yellow oil product $(92 \%)$, ESI-MS $(\mathrm{m} / \mathrm{z})$ $383.0\left(\mathrm{M}+\mathrm{H}^{+}\right),[\boldsymbol{\alpha}]_{\mathrm{D}}-260\left(c 1.0 ; \mathrm{CHCl}_{3}\right)$. IR $\left(\mathrm{KBr}, \mathrm{cm}^{-1}\right)$ : $2934(\nu, \mathrm{C}-\mathrm{H}), 2666(\nu, \mathrm{O}-\mathrm{H}), 1626(\nu, \mathrm{C}=\mathrm{N}), 1514(\nu, \mathrm{C}=\mathrm{C})$, $1291(\nu, \mathrm{C}-\mathrm{N}), 1223,1165(\nu, \mathrm{C}-\mathrm{O}), 835,799(\delta, \mathrm{C}-\mathrm{H}), 647$. ${ }^{1} \mathrm{H}-\mathrm{NMR}\left(\mathrm{CDCl}_{3}, 500 \mathrm{MHz}, \mathrm{ppm}\right): \delta 13.76(\mathrm{~s}, 2 \mathrm{H}, 2 \mathrm{OH})$, $8.08(\mathrm{~s}, 2 \mathrm{H}, 2 \mathrm{CH}=\mathrm{N}), 6.99(\mathrm{~d}, J=8.5,2 \mathrm{H}, \operatorname{ArH}), 6.35(\mathrm{~d}$, $J=2.5,2 \mathrm{H}, \mathrm{ArH}), 6.30$ (dd, $J=8.5 ; 2.5,2 \mathrm{H}, \mathrm{ArH}), 3.76(\mathrm{~s}, 6 \mathrm{H}$, $2 \mathrm{MeO}), 3.22(\mathrm{~m}, 2 \mathrm{H}, \mathrm{CyH}), 1.96(\mathrm{~m}, 2 \mathrm{H}, \mathrm{CyH}), 1.86(\mathrm{~m}, 2 \mathrm{H}$, $\mathrm{CyH}), 1.67(\mathrm{~m}, 2 \mathrm{H}, \mathrm{CyH}), 1.45(\mathrm{~m}, 2 \mathrm{H}, \mathrm{CyH}) .{ }^{13} \mathrm{C}-\mathrm{NMR}$ $\left(\mathrm{CDCl}_{3}, 125 \mathrm{MHz}, \mathrm{ppm}\right): \delta 165.05(2 \mathrm{C}, \mathrm{C}-\mathrm{OH}), 163.73(2 \mathrm{C}$, $\mathrm{C}=\mathrm{N}), 163.49$ (2C, $\mathrm{C}-\mathrm{OMe}), 132.78\left(2 \mathrm{C}, \mathrm{C}_{\mathrm{Ar}}\right), 112.22(2 \mathrm{C}$, $\left.\mathrm{C}_{\mathrm{Ar}}\right), 106.24\left(2 \mathrm{C}, \mathrm{C}_{\mathrm{Ar}}\right), 101.13\left(2 \mathrm{C}, \mathrm{C}_{\mathrm{Ar}}\right), 71.53\left(2 \mathrm{C}, \mathrm{C}_{\mathrm{Cy}}\right)$, $55.30(2 \mathrm{C}, \mathrm{MeO}), 33.07\left(2 \mathrm{C}, \mathrm{C}_{\mathrm{Cy}}\right), 24.24\left(2 \mathrm{C}, \mathrm{C}_{\mathrm{Cy}}\right)$.

3.8. N,N'-Bis(4-methoxysalicylidene)-(S,S $)$-1,2-cyclohexanediamine $\left((\mathrm{S}) \mathrm{L}_{4} \mathrm{H}_{2}\right)$. Yellow oil product $(91 \%), \mathbf{E S I}-\mathbf{M S}(\mathrm{m} / \mathrm{z})$ $383.0\left(\mathrm{M}+\mathrm{H}^{+}\right),[\boldsymbol{\alpha}]_{\mathbf{D}}+261\left(\right.$ c 1.0; $\left.\mathrm{CHCl}_{3}\right)$. IR $\left(\mathrm{KBr}, \mathrm{cm}^{-1}\right)$ : $2932(\nu, \mathrm{C}-\mathrm{H}), 2664(\nu, \mathrm{O}-\mathrm{H}), 1617(\nu, \mathrm{C}=\mathrm{N}), 1512(\nu, \mathrm{C}=\mathrm{C})$, $1288(\nu, \mathrm{C}-\mathrm{N}), 1221,1163(\nu, \mathrm{C}-\mathrm{O}), 832,796(\delta, \mathrm{C}-\mathrm{H}), 645$. ${ }^{1} \mathbf{H}-\mathbf{N M R}\left(\mathrm{CDCl}_{3}, 500 \mathrm{MHz}, \mathrm{ppm}\right): \delta 13.79(\mathrm{~s}, 2 \mathrm{H}, 2 \mathrm{OH})$, $8.09(\mathrm{~s}, 2 \mathrm{H}, 2 \mathrm{CH}=\mathrm{N}), 6.99(\mathrm{~d}, J=8.5,2 \mathrm{H}, \mathrm{ArH}), 6.35$ (d, $J=2.5,2 \mathrm{H}, \mathrm{ArH}), 6.30(\mathrm{dd}, J=7.5 ; 2.5,2 \mathrm{H}, \mathrm{ArH}), 3.76(\mathrm{~s}, 6 \mathrm{H}$, $2 \mathrm{MeO}), 3.22(\mathrm{~m}, 2 \mathrm{H}, \mathrm{CyH}), 1.96(\mathrm{~m}, 2 \mathrm{H}, \mathrm{CyH}), 1.86(\mathrm{~m}, 2 \mathrm{H}$, CyH), 1.67 (m, 2H, CyH), 1.45 (m, 2H, CyH). ${ }^{13}$ C-NMR $\left(\mathrm{CDCl}_{3}, 125 \mathrm{MHz}, \mathrm{ppm}\right): \delta 164.90(2 \mathrm{C}, \mathrm{C}-\mathrm{OH}), 163.74$ (2C, $\mathrm{C}=\mathrm{N}), 163.45(2 \mathrm{C}, \mathrm{C}-\mathrm{OMe}), 132.75\left(2 \mathrm{C}, \mathrm{C}_{\mathrm{Ar}}\right), 112.26(2 \mathrm{C}$, $\left.\mathrm{C}_{\mathrm{Ar}}\right), 106.21\left(2 \mathrm{C}, \mathrm{C}_{\mathrm{Ar}}\right), 101.12\left(2 \mathrm{C}, \mathrm{C}_{\mathrm{Ar}}\right), 71.60\left(2 \mathrm{C}, \mathrm{C}_{\mathrm{Cy}}\right)$, $55.29(2 \mathrm{C}, \mathrm{MeO}), 33.08\left(2 \mathrm{C}, \mathrm{C}_{\mathrm{Cy}}\right), 24.24\left(2 \mathrm{C}, \mathrm{C}_{\mathrm{Cy}}\right)$.

3.9. $N, N^{\prime}$-Bis(5-methoxysalicylidene)-(R, $\left.R^{\prime}\right)$-1,2-cyclohexanediamine $\left((\mathrm{R}) \mathrm{LSH}_{2}\right)$. Yellow solid product (92\%), ESI-MS (m/ z) $383.0\left(\mathrm{M}+\mathrm{H}^{+}\right),[\boldsymbol{\alpha}]_{\mathbf{D}}-298\left(\right.$ c 1.0; $\left.\mathrm{CHCl}_{3}\right)$. IR $\left(\mathrm{KBr}, \mathrm{cm}^{-1}\right)$ : $2939(\nu, \mathrm{C}-\mathrm{H}), 2581(\nu, \mathrm{O}-\mathrm{H}), 1631(\nu, \mathrm{C}=\mathrm{N}), 1492(\nu, \mathrm{C}=\mathrm{C})$, $1269(\nu, \mathrm{C}-\mathrm{N}), 1161(\nu, \mathrm{C}-\mathrm{O}), 1095,810,785(\delta, \mathrm{C}-\mathrm{H}), 670$. ${ }^{1} \mathrm{H}-\mathrm{NMR}\left(\mathrm{CDCl}_{3}, 500 \mathrm{MHz}, \mathrm{ppm}\right): \delta 12.79(\mathrm{~s}, 2 \mathrm{H}, 2 \mathrm{OH})$, $8.19(\mathrm{~s}, 2 \mathrm{H}, 2 \mathrm{CH}=\mathrm{N}), 6.86(\mathrm{dd}, J=9.0 ; 3.0,2 \mathrm{H}, \mathrm{ArH}), 6.81(\mathrm{~d}$, $J=9.0,2 \mathrm{H}, \mathrm{ArH}), 6.64(\mathrm{~d}, J=3.0,2 \mathrm{H}, \mathrm{ArH}), 3.70(\mathrm{~s}, 6 \mathrm{H}, 2$ $\mathrm{MeO}), 3.29$ (m, 2H, CyH), $1.94(\mathrm{~m}, 2 \mathrm{H}, \mathrm{CyH}), 1.88(\mathrm{~m}, 2 \mathrm{H}$,
CyH), 1.72 (m, 2H, CyH), 1.48 (m, 2H, CyH). ${ }^{13} \mathrm{C}-\mathbf{N M R}$ $\left(\mathrm{CDCl}_{3}, 125 \mathrm{MHz}, \mathrm{ppm}\right): \delta 164.48(2 \mathrm{C}, \mathrm{C}-\mathrm{OH}), 155.08(2 \mathrm{C}$, $\mathrm{C}=\mathrm{N}), 151.99(2 \mathrm{C}, \mathrm{C}-\mathrm{OMe}), 119.41\left(2 \mathrm{C}, \mathrm{C}_{\mathrm{Ar}}\right), 118.26(2 \mathrm{C}$, $\left.\mathrm{C}_{\mathrm{Ar}}\right), 117.47\left(2 \mathrm{C}, \mathrm{C}_{\mathrm{Ar}}\right), 114.87\left(2 \mathrm{C}, \mathrm{C}_{\mathrm{Ar}}\right), 72.78\left(2 \mathrm{C}, \mathrm{C}_{\mathrm{Cy}}\right)$, $55.90(2 \mathrm{C}, \mathrm{MeO}), 33.05\left(2 \mathrm{C}, \mathrm{C}_{\mathrm{Cy}}\right), 24.17\left(2 \mathrm{C}, \mathrm{C}_{\mathrm{Cy}}\right)$.

3.10. $N, N^{\prime}$-Bis(5-methoxysalicylidene)-(S,S $)$-1,2-cyclohexanediamine $\left((\mathrm{S}) \mathrm{L} \mathrm{H}_{2}\right)$. Yellow solid product (93\%), ESI-MS (m/ z) $383.0\left(\mathrm{M}+\mathrm{H}^{+}\right),[\boldsymbol{\alpha}]_{\mathbf{D}}+300\left(\right.$ c 1.0; $\left.\mathrm{CHCl}_{3}\right)$. IR $\left(\mathrm{KBr}, \mathrm{cm}^{-1}\right)$ : $2937(\nu, \mathrm{C}-\mathrm{H}), 2579(\nu, \mathrm{O}-\mathrm{H}), 1630(\nu, \mathrm{C}=\mathrm{N}), 1490(\nu$, $\mathrm{C}=\mathrm{C}), 1267(\nu, \mathrm{C}-\mathrm{N}), 1160(\nu, \mathrm{C}-\mathrm{O}), 1095,809,784(\delta$, C-H), 670. ${ }^{1} \mathrm{H}-\mathrm{NMR}\left(\mathrm{CDCl}_{3}, 500 \mathrm{MHz}, \mathrm{ppm}\right): \delta 12.80(\mathrm{~s}$, $2 \mathrm{H}, 2 \mathrm{OH}), 8.19(\mathrm{~s}, 2 \mathrm{H}, 2 \mathrm{CH}=\mathrm{N}), 6.85(\mathrm{dd}, J=9.0 ; 3.0,2 \mathrm{H}$, $\operatorname{ArH}), 6.81(\mathrm{~d}, J=9.0,2 \mathrm{H}, \operatorname{ArH}), 6.64(\mathrm{~d}, J=3.0,2 \mathrm{H}, \operatorname{ArH})$, $3.70(\mathrm{~s}, 6 \mathrm{H}, 2 \mathrm{MeO}), 3.29(\mathrm{~m}, 2 \mathrm{H}, \mathrm{CyH}), 1.94(\mathrm{~m}, 2 \mathrm{H}, \mathrm{CyH})$, $1.88(\mathrm{~m}, 2 \mathrm{H}, \mathrm{CyH}), 1.72(\mathrm{~m}, 2 \mathrm{H}, \mathrm{CyH}), 1.47$ (m, 2H, CyH). ${ }^{13} \mathrm{C}-\mathrm{NMR}\left(\mathrm{CDCl}_{3}, 125 \mathrm{MHz}, \mathrm{ppm}\right): \delta 164.49(2 \mathrm{C}, \mathrm{C}-\mathrm{OH})$, $155.08(2 \mathrm{C}, \mathrm{C}=\mathrm{N}), 151.99(2 \mathrm{C}, \mathrm{C}-\mathrm{OMe}), 119.42\left(2 \mathrm{C}, \mathrm{C}_{\mathrm{Ar}}\right)$, $118.26\left(2 \mathrm{C}, \mathrm{C}_{\mathrm{Ar}}\right), 117.47\left(2 \mathrm{C}, \mathrm{C}_{\mathrm{Ar}}\right), 114.87\left(2 \mathrm{C}, \mathrm{C}_{\mathrm{Ar}}\right), 72.76$ $\left(2 \mathrm{C}, \mathrm{C}_{\mathrm{Cy}}\right), 55.90(2 \mathrm{C}, \mathrm{MeO}), 33.04\left(2 \mathrm{C}, \mathrm{C}_{\mathrm{Cy}}\right), 24.17\left(2 \mathrm{C}, \mathrm{C}_{\mathrm{Cy}}\right)$.

3.11. $N, N^{\prime}$-Bis(6-methoxysalicylidene)-( $\left.R, R^{\prime}\right)-1,2$-cyclohexanediamine $\left((\mathrm{R}) \mathrm{L}_{6} \mathrm{H}_{2}\right)$. Yellow solid product (91\%), ESI-MS (m/ z) $383.1\left(\mathrm{M}+\mathrm{H}^{+}\right),[\boldsymbol{\alpha}]_{\mathbf{D}}-240\left(c 1.0 ; \mathrm{CHCl}_{3}\right)$. IR $\left(\mathrm{KBr}, \mathrm{cm}^{-1}\right)$ : $2940(\nu, \mathrm{C}-\mathrm{H}), 2550(\nu, \mathrm{O}-\mathrm{H}), 1621(\nu, \mathrm{C}=\mathrm{N}), 1465(\nu, \mathrm{C}=\mathrm{C})$, $1294(\nu, \mathrm{C}-\mathrm{N}), 1250,1169(\nu, \mathrm{C}-\mathrm{O}), 864,781(\delta, \mathrm{C}-\mathrm{H}), 725$, 652. ${ }^{1} \mathrm{H}-\mathrm{NMR}\left(\mathrm{CDCl}_{3}, 500 \mathrm{MHz}, \mathrm{ppm}\right): \delta 14.32(\mathrm{~s}, 2 \mathrm{H}$, $2 \mathrm{OH}), 8.68(\mathrm{~s}, 2 \mathrm{H}, 2 \mathrm{CH}=\mathrm{N}), 7.14(\mathrm{t}, J=8.0,2 \mathrm{H}, \mathrm{ArH}), 6.46$ $(\mathrm{d}, J=8.5,2 \mathrm{H}, \mathrm{ArH}), 6.19$ (d, J=8.5, 2H, ArH), $3.71(\mathrm{~s}, 6 \mathrm{H}, 2$ $\mathrm{MeO}), 3.29$ (m, 2H, CyH), $1.95(\mathrm{~m}, 2 \mathrm{H}, \mathrm{CyH}), 1.85(\mathrm{~m}, 2 \mathrm{H}$, $\mathrm{CyH}), 1.68$ (m, 2H, CyH), 1.45 (m, 2H, CyH). ${ }^{13} \mathrm{C}-\mathbf{N M R}$ $\left(\mathrm{CDCl}_{3}, 125 \mathrm{MHz}, \mathrm{ppm}\right): \delta 164.09(2 \mathrm{C}, \mathrm{C}-\mathrm{OH}), 160.98$ (2C, $\mathrm{C}=\mathrm{N}), 159.71$ (2C, C-OMe), $133.24\left(2 \mathrm{C}, \mathrm{C}_{\mathrm{Ar}}\right), 110.15(2 \mathrm{C}$, $\left.\mathrm{C}_{\mathrm{Ar}}\right), 108.01\left(2 \mathrm{C}, \mathrm{C}_{\mathrm{Ar}}\right), 99.59\left(2 \mathrm{C}, \mathrm{C}_{\mathrm{Ar}}\right), 72.10\left(2 \mathrm{C}, \mathrm{C}_{\mathrm{Cy}}\right)$, $55.52(2 \mathrm{C}, \mathrm{MeO}), 33.15\left(2 \mathrm{C}, \mathrm{C}_{\mathrm{Cy}}\right), 24.20\left(2 \mathrm{C}, \mathrm{C}_{\mathrm{Cy}}\right)$.

3.12. $N, N^{\prime}$-Bis(6-methoxysalicylidene)-(S, $\left.S^{\prime}\right)-1,2$-cyclohexanediamine $\left((\mathrm{S}) \mathrm{L}_{6} \mathrm{H}_{2}\right)$. Yellow solid product (91\%), ESI-MS (m/z) $383.0\left(\mathrm{M}+\mathrm{H}^{+}\right),[\boldsymbol{\alpha}]_{\mathbf{D}}+239\left(c 1.0 ; \mathrm{CHCl}_{3}\right) . \mathbf{I R}\left(\mathrm{KBr}, \mathrm{cm}^{-1}\right)$ : $2940(\nu, \mathrm{C}-\mathrm{H}), 2548(\nu, \mathrm{O}-\mathrm{H}), 1617(\nu, \mathrm{C}=\mathrm{N}), 1464(\nu, \mathrm{C}=\mathrm{C})$, $1294(\nu, \mathrm{C}-\mathrm{N}), 1247,1169(\nu, \mathrm{C}-\mathrm{O}), 864,781(\delta, \mathrm{C}-\mathrm{H}), 725$, 653. ${ }^{1} \mathrm{H}-\mathrm{NMR}\left(\mathrm{CDCl}_{3}, 500 \mathrm{MHz}, \mathrm{ppm}\right): \delta 14.30(\mathrm{~s}, 2 \mathrm{H}$, $2 \mathrm{OH}), 8.68(\mathrm{~s}, 2 \mathrm{H}, 2 \mathrm{CH}=\mathrm{N}), 7.14(\mathrm{t}, J=8.0,2 \mathrm{H}, \mathrm{ArH}), 6.46$ (d, $J=8.0,2 \mathrm{H}, \mathrm{ArH}), 6.19$ (d, $J=8.0,2 \mathrm{H}, \mathrm{ArH}), 3.71(\mathrm{~s}, 6 \mathrm{H}, 2$ $\mathrm{MeO}), 3.29$ (m, 2H, CyH), 1.95 (m, 2H, CyH), 1.85 (m, 2H, $\mathrm{CyH}), 1.68(\mathrm{~m}, 2 \mathrm{H}, \mathrm{CyH}), 1.44(\mathrm{~m}, 2 \mathrm{H}, \mathrm{CyH}) .{ }^{13} \mathrm{C}-\mathrm{NMR}$ $\left(\mathrm{CDCl}_{3}, 125 \mathrm{MHz}, \mathrm{ppm}\right): \delta 164.07(2 \mathrm{C}, \mathrm{C}-\mathrm{OH}), 160.99$ (2C, $\mathrm{C}=\mathrm{N}), 159.72(2 \mathrm{C}, \mathrm{C}-\mathrm{OMe}), 133.24\left(2 \mathrm{C}, \mathrm{C}_{\mathrm{Ar}}\right), 110.15(2 \mathrm{C}$, $\left.\mathrm{C}_{\mathrm{Ar}}\right), 108.03\left(2 \mathrm{C}, \mathrm{C}_{\mathrm{Ar}}\right), 99.61\left(2 \mathrm{C}, \mathrm{C}_{\mathrm{Ar}}\right), 72.12\left(2 \mathrm{C}, \mathrm{C}_{\mathrm{Cy}}\right)$, $55.53(2 \mathrm{C}, \mathrm{MeO}), 33.17\left(2 \mathrm{C}, \mathrm{C}_{\mathrm{Cy}}\right), 24.21\left(2 \mathrm{C}, \mathrm{C}_{\mathrm{Cy}}\right)$.

\section{Preparation of Chiral Salen Platinum(II) Complexes}

$\mathrm{K}_{2} \mathrm{PtCl}_{4}$ (212 mg, $0.5 \mathrm{mmol}$ ) was dissolved in $5 \mathrm{~mL}$ DMSO and then ligand $\mathrm{L}(0.5 \mathrm{mmol})$ dissolving in $5 \mathrm{~mL}$ DMSO was added. The reaction mixture was stirred at room 
temperature for $0.5 \mathrm{~h}$ at $\mathrm{pH}$ 9.5. The reaction mixture was refluxed for $3 \mathrm{~h}$, and then the mixture was cooled until room temperature. The yellow precipitate was filtered and washed by cool ethanol several times and dried in vacuo.

$[\operatorname{Pt}(R)(\mathrm{L} 1)]$ : yellow precipitate $(72 \%), \mathbf{E S I}-\mathbf{M S}(\mathrm{m} / \mathrm{z})$ $516.0\left(\mathrm{M}+\mathrm{H}^{+}\right),[\boldsymbol{\alpha}]_{\mathbf{D}}-302(c 0.1 ; \mathrm{DMSO})$. IR $\left(\mathrm{KBr}, \mathrm{cm}^{-1}\right)$ : $2925(\nu, \mathrm{C}-\mathrm{H}), 1600(\nu, \mathrm{C}=\mathrm{N}), 1448(\nu, \mathrm{C}=\mathrm{C}), 1317,1190(\nu$, C-N), 1150 ( $\nu, C-O), 745(\delta, \mathrm{C}-\mathrm{H}), 567,469 .{ }^{1} \mathbf{H}-\mathbf{N M R}$ $\left(\mathrm{CDCl}_{3}, 500 \mathrm{MHz}, \mathrm{ppm}\right): \delta 7.68(\mathrm{~s}, 2 \mathrm{H}, 2 \mathrm{CH}=\mathrm{N}), 7.41(\mathrm{dt}$, $J=8.5 ; 1.5,2 \mathrm{H}, \operatorname{ArH}), 7.14(\mathrm{~d}, J=8.5,2 \mathrm{H}, \operatorname{ArH}), 7.03$ (dd, $J=8.0,2 \mathrm{H}, \mathrm{ArH}), 6.53(\mathrm{dt}, J=7.5 ; 1.0,2 \mathrm{H}, \mathrm{ArH}), 3.68(\mathrm{~m}$, 2H, CyH), 2.50 (m, 2H, CyH), $1.91(\mathrm{~m}, 2 \mathrm{H}, \mathrm{CyH}), 1.44$ (m, $4 \mathrm{H}, \mathrm{CyH}) .{ }^{13} \mathrm{C}-\mathbf{N M R}\left(\mathrm{CDCl}_{3}, 125 \mathrm{MHz}, \mathrm{ppm}\right): \delta 163.35(2 \mathrm{C}$, $\mathrm{C}-\mathrm{O}), 150.71(2 \mathrm{C}, \mathrm{C}=\mathrm{N}), 133.95\left(2 \mathrm{C}, \mathrm{C}_{\mathrm{Ar}}\right), 133.56\left(2 \mathrm{C}, \mathrm{C}_{\mathrm{Ar}}\right)$, $122.13\left(4 \mathrm{C}, \mathrm{C}_{\mathrm{Ar}}\right), 115.70\left(2 \mathrm{C}, \mathrm{C}_{\mathrm{Ar}}\right), 73.64\left(2 \mathrm{C}, \mathrm{C}_{\mathrm{Cy}}\right), 27.69$ $\left(2 \mathrm{C}, \mathrm{C}_{\mathrm{Cy}}\right), 24.59\left(2 \mathrm{C}, \mathrm{C}_{\mathrm{Cy}}\right)$.

$[\mathrm{Pt}(S)(\mathrm{L} 1)]$ : yellow precipitate $(71 \%)$, ESI-MS (m/z) $516.0\left(\mathrm{M}+\mathrm{H}^{+}\right),[\boldsymbol{\alpha}]_{\mathbf{D}}+299(c 0.1 ; \mathrm{DMSO}) . \mathbf{I R}\left(\mathrm{KBr}, \mathrm{cm}^{-1}\right)$ : $2933(\nu, \mathrm{C}-\mathrm{H}), 1601(\nu, \mathrm{C}=\mathrm{N}), 1447(\nu, \mathrm{C}=\mathrm{C}), 1317,1190(\nu$, C-N), 1150 ( $\nu, C-O), 749(\delta, \mathrm{C}-\mathrm{H}), 568,471 .{ }^{1} \mathbf{H}-\mathbf{N M R}$ $\left(\mathrm{CDCl}_{3}, 500 \mathrm{MHz}, \mathrm{ppm}\right): \delta 7.66(\mathrm{~s}, 2 \mathrm{H}, 2 \mathrm{CH}=\mathrm{N}), 7.40(\mathrm{dt}$, $J=8.5 ; 1.5,2 \mathrm{H}, \operatorname{ArH}), 7.13(\mathrm{~d}, J=8.5,2 \mathrm{H}, \operatorname{ArH}), 7.01$ (dd, $J=8.0,2 \mathrm{H}, \mathrm{ArH}), 6.52(\mathrm{dt}, J=7.5 ; 1.0,2 \mathrm{H}, \mathrm{ArH}), 3.68(\mathrm{~m}$, 2H, CyH), 2.49 (m, 2H, CyH), 1.90 (m, 2H, CyH), 1.43 (m, 4H, CyH $) .{ }^{13} \mathrm{C}-\mathrm{NMR}\left(\mathrm{CDCl}_{3}, 125 \mathrm{MHz}, \mathrm{ppm}\right): \delta 163.39(2 \mathrm{C}$, C-O), $150.73(2 \mathrm{C}, \mathrm{C}=\mathrm{N}), 133.91\left(2 \mathrm{C}, \mathrm{C}_{\mathrm{Ar}}\right), 133.60\left(2 \mathrm{C}, \mathrm{C}_{\mathrm{Ar}}\right)$, $122.15\left(4 \mathrm{C}, \mathrm{C}_{\mathrm{Ar}}\right), 115.72\left(2 \mathrm{C}, \mathrm{C}_{\mathrm{Ar}}\right), 73.65\left(2 \mathrm{C}, \mathrm{C}_{\mathrm{Cy}}\right), 27.71$ $\left(2 \mathrm{C}, \mathrm{C}_{\mathrm{Cy}}\right), 24.60\left(2 \mathrm{C}, \mathrm{C}_{\mathrm{Cy}}\right)$.

$[\mathrm{Pt}(R)(\mathrm{L} 2)]$ : yellow precipitate $(72 \%), \mathbf{E S I}-\mathbf{M S}(\mathrm{m} / \mathrm{z})$ $552.0\left(\mathrm{M}+\mathrm{H}^{+}\right),[\boldsymbol{\alpha}]_{\mathbf{D}}-223\left(\right.$ c 0.03; DMSO). IR $\left(\mathrm{KBr}, \mathrm{cm}^{-1}\right)$ : $2937(\nu, \mathrm{C}-\mathrm{H}), 1623(\nu, \mathrm{C}=\mathrm{N}), 1468(\nu, \mathrm{C}=\mathrm{C}), 1312,1197(\nu$, C-N), $1142(\nu, \mathrm{C}-\mathrm{O}), 814,790(\delta, \mathrm{C}-\mathrm{H}), 571,471 .{ }^{\mathbf{1}} \mathbf{H}-\mathbf{N M R}$ (DMSO- $\left.d^{6}, 500 \mathrm{MHz}, \mathrm{ppm}\right): \delta 8.43(\mathrm{~s}, 2 \mathrm{H}, 2 \mathrm{CH}=\mathrm{N}), 7.48$ (dd, $J=9.5 ; 3.0,2 \mathrm{H}, \mathrm{ArH}), 7.33$ (m, 2H, ArH), 6.88 (q, J= 5.0, 2H, ArH), 3.56 (m, 2H, CyH), $2.72(\mathrm{~m}, 2 \mathrm{H}, \mathrm{CyH}), 1.80$ (m, 2H, CyH), 1.51 (m, 2H, CyH), 1.35 (m, 2H, CyH). ${ }^{13} \mathbf{C}-\mathbf{N M R}$ (DMSO- $\left.d^{6}, 125 \mathrm{MHz}, \mathrm{ppm}\right): \delta 159.28(2 \mathrm{C}, \mathrm{C}-\mathrm{O}), 153.34$ and $151.51(2 \mathrm{C}, \mathrm{C}-\mathrm{F}), 151.30(2 \mathrm{C}, \mathrm{C}=\mathrm{N}), 121.42$ and $121.36(2 \mathrm{C}$, $\left.\mathrm{C}_{\mathrm{Ar}}\right), 121.15$ and $120.95\left(2 \mathrm{C}, \mathrm{C}_{\mathrm{Ar}}\right), 120.57$ and $120.50(2 \mathrm{C}$, $\left.\mathrm{C}_{\mathrm{Ar}}\right), 116.69$ and $116.51\left(2 \mathrm{C}, \mathrm{C}_{\mathrm{Ar}}\right), 73.49\left(2 \mathrm{C}, \mathrm{C}_{\mathrm{Cy}}\right), 27.13$ $\left(2 \mathrm{C}, \mathrm{C}_{\mathrm{Cy}}\right), 23.63\left(2 \mathrm{C}, \mathrm{C}_{\mathrm{Cy}}\right)$.

$[\operatorname{Pt}(S)(\mathrm{L} 2)]$ : yellow precipitate $(73 \%)$, ESI-MS $(\mathrm{m} / \mathrm{z})$ $551.9\left(\mathrm{M}+\mathrm{H}^{+}\right),[\boldsymbol{\alpha}]_{\mathbf{D}}+221\left(c \mathrm{0} 03\right.$; DMSO). IR $\left(\mathrm{KBr}, \mathrm{cm}^{-1}\right)$ : $2938(\nu, \mathrm{C}-\mathrm{H}), 1622(\nu, \mathrm{C}=\mathrm{N}), 1464(\nu, \mathrm{C}=\mathrm{C}), 1311,1198(\nu$, C-N), $1141(\nu, \mathrm{C}-\mathrm{O}), 814,789(\delta, \mathrm{C}-\mathrm{H}), 571,470 .{ }^{1} \mathbf{H}-\mathbf{N M R}$ (DMSO- $\left.d^{6}, 500 \mathrm{MHz}, \mathrm{ppm}\right): \delta 8.43(\mathrm{~s}, 2 \mathrm{H}, 2 \mathrm{CH}=\mathrm{N}), 7.48$ (dd, $J=9.5 ; 3.5,2 \mathrm{H}, \mathrm{ArH}), 7.33(\mathrm{~m}, 2 \mathrm{H}, \mathrm{ArH}), 6.88$ (q, $J=5.0$, 2H, ArH), $3.56(\mathrm{~m}, 2 \mathrm{H}, \mathrm{CyH}), 2.72(\mathrm{~m}, 2 \mathrm{H}, \mathrm{CyH}), 1.80(\mathrm{~m}$, 2H, CyH), 1.51 (m, 2H, CyH), 1.35 (m, 2H, CyH). ${ }^{13} \mathbf{C}-\mathbf{N M R}$ (DMSO- $\left.d^{6}, 125 \mathrm{MHz}, \mathrm{ppm}\right): \delta 159.28$ (2C, C-O), 153.36 and $151.53(2 \mathrm{C}, \mathrm{C}-\mathrm{F}), 151.34(2 \mathrm{C}, \mathrm{C}=\mathrm{N}), 121.44$ and $121.38(2 \mathrm{C}$, $\left.\mathrm{C}_{\mathrm{Ar}}\right), 121.17$ and $120.98\left(2 \mathrm{C}, \mathrm{C}_{\mathrm{Ar}}\right), 120.59$ and $120.52(2 \mathrm{C}$, $\left.\mathrm{C}_{\mathrm{Ar}}\right), 116.71$ and $116.53\left(2 \mathrm{C}, \mathrm{C}_{\mathrm{Ar}}\right), 73.51\left(2 \mathrm{C}, \mathrm{C}_{\mathrm{Cy}}\right), 27.14(2 \mathrm{C}$, $\left.\mathrm{C}_{\mathrm{Cy}}\right), 23.64$ (2C, $\left.\mathrm{C}_{\mathrm{Cy}}\right)$.

$[\operatorname{Pt}(R)(\mathrm{L} 3)]$ : yellow precipitate $(67 \%)$, ESI-MS $(\mathrm{m} / \mathrm{z})$ $576.0\left(\mathrm{M}+\mathrm{H}^{+}\right),[\boldsymbol{\alpha}]_{\mathbf{D}}-155\left(c\right.$ 0.03; DMSO). IR $\left(\mathrm{KBr}, \mathrm{cm}^{-1}\right)$ : $2927(\nu, \mathrm{C}-\mathrm{H}), 1623(\nu, \mathrm{C}=\mathrm{N}), 1469(\nu, \mathrm{C}=\mathrm{C}), 1316,1217(\nu$, C-N), $1112(\nu, \mathrm{C}-\mathrm{O}), 1085,854,727(\delta, \mathrm{C}-\mathrm{H}), 564,460 .{ }^{1} \mathbf{H}-$ NMR (DMSO- $\left.d^{6}, 500 \mathrm{MHz}, \mathrm{ppm}\right): \delta 8.36(\mathrm{~s}, 2 \mathrm{H}, 2 \mathrm{CH}=\mathrm{N})$, $7.18(\mathrm{dd}, J=8.5 ; 1.5,2 \mathrm{H}, \mathrm{ArH}), 7.03(\mathrm{dd}, J=7.5 ; 1.5,2 \mathrm{H}$, $\mathrm{ArH}), 6.53(\mathrm{t}, J=8.0,2 \mathrm{H}, \mathrm{ArH}), 3.77(\mathrm{~s}, 6 \mathrm{H}, 2 \mathrm{MeO}), 3.54(\mathrm{~m}$, 2H, CyH), 2.76 (m, 2H, CyH), $1.80(\mathrm{~m}, 2 \mathrm{H}, \mathrm{CyH}), 1.51$ (m, 2H, CyH), 1.35 (m, 2H, CyH). ${ }^{13} \mathrm{C}-\mathrm{NMR}$ (DMSO- $d^{6}$, $125 \mathrm{MHz}, \mathrm{ppm}): \delta 154.20(2 \mathrm{C}, \mathrm{C}-\mathrm{O}), 151.62(2 \mathrm{C}, \mathrm{C}=\mathrm{N})$, 150.95 (2C, C-OMe), $125.56\left(2 \mathrm{C}, \mathrm{C}_{\mathrm{Ar}}\right), 121.70\left(2 \mathrm{C}, \mathrm{C}_{\mathrm{Ar}}\right)$, $114.44\left(2 \mathrm{C}, \mathrm{C}_{\mathrm{Ar}}\right), 113.75\left(2 \mathrm{C}, \mathrm{C}_{\mathrm{Ar}}\right), 73.34\left(2 \mathrm{C}, \mathrm{C}_{\mathrm{Cy}}\right), 55.41$ (2C, $2 \mathrm{MeO}), 27.08\left(2 \mathrm{C}, \mathrm{C}_{\mathrm{Cy}}\right), 23.71\left(2 \mathrm{C}, \mathrm{C}_{\mathrm{Cy}}\right)$.

$[\mathrm{Pt}(S)(\mathrm{L} 3)]$ : yellow precipitate $(69 \%)$, ESI-MS $(\mathrm{m} / \mathrm{z})$ $576.0\left(\mathrm{M}+\mathrm{H}^{+}\right),[\boldsymbol{\alpha}]_{\mathbf{D}}+157(c 0.03 ; \mathrm{DMSO}) . \mathbf{I R}\left(\mathrm{KBr}, \mathrm{cm}^{-1}\right)$ : $2928(\nu, \mathrm{C}-\mathrm{H}), 1616(\nu, \mathrm{C}=\mathrm{N}), 1468(\nu, \mathrm{C}=\mathrm{C}), 1316,1213(\nu$, C-N), 1115 ( $\nu, \mathrm{C}-\mathrm{O}), 1083,854,727(\delta, \mathrm{C}-\mathrm{H}), 563,459 .{ }^{\mathbf{1}} \mathbf{H}-$ NMR (DMSO- $\left.d^{6}, 500 \mathrm{MHz}, \mathrm{ppm}\right): \delta 8.36(\mathrm{~s}, 2 \mathrm{H}, 2 \mathrm{CH}=\mathrm{N})$, $7.18(\mathrm{dd}, J=8.5 ; 1.5,2 \mathrm{H}, \mathrm{ArH}), 7.03(\mathrm{dd}, J=7.5 ; 1.5,2 \mathrm{H}$, ArH), 6.53 (t, $J=8.0,2 \mathrm{H}, \mathrm{ArH}), 3.77(\mathrm{~s}, 6 \mathrm{H}, 2 \mathrm{MeO}), 3.54(\mathrm{~m}$, $2 \mathrm{H}, \mathrm{CyH}), 2.76(\mathrm{~m}, 2 \mathrm{H}, \mathrm{CyH}), 1.80(\mathrm{~m}, 2 \mathrm{H}, \mathrm{CyH}), 1.51$ (m, 2H, CyH), $1.35(\mathrm{~m}, 2 \mathrm{H}, \mathrm{CyH}) .{ }^{13} \mathrm{C}-\mathrm{NMR}$ (DMSO- $d^{6}$, $125 \mathrm{MHz}, \mathrm{ppm}): \delta 154.20(2 \mathrm{C}, \mathrm{C}-\mathrm{O}), 151.64(2 \mathrm{C}, \mathrm{C}=\mathrm{N})$, 150.96 (2C, C-OMe), $125.56\left(2 \mathrm{C}, \mathrm{C}_{\mathrm{Ar}}\right), 121.69\left(2 \mathrm{C}, \mathrm{C}_{\mathrm{Ar}}\right)$, $114.44\left(2 \mathrm{C}, \mathrm{C}_{\mathrm{Ar}}\right), 113.76\left(2 \mathrm{C}, \mathrm{C}_{\mathrm{Ar}}\right), 73.35\left(2 \mathrm{C}, \mathrm{C}_{\mathrm{Cy}}\right), 55.41$ (2C, $2 \mathrm{MeO}), 27.10\left(2 \mathrm{C}, \mathrm{C}_{\mathrm{Cy}}\right), 23.72\left(2 \mathrm{C}, \mathrm{C}_{\mathrm{Cy}}\right)$.

$[\operatorname{Pt}(R)(\mathrm{L} 4)]$ : yellow precipitate $(71 \%)$, ESI-MS $(\mathrm{m} / \mathrm{z})$ $576.1\left(\mathrm{M}+\mathrm{H}^{+}\right),[\boldsymbol{\alpha}]_{\mathbf{D}^{-}}-87\left(c\right.$ 0.03; DMSO). IR $\left(\mathrm{KBr}, \mathrm{cm}^{-1}\right)$ : $2932(\nu, \mathrm{C}-\mathrm{H}), 1607(\nu, \mathrm{C}=\mathrm{N}), 1442(\nu, \mathrm{C}=\mathrm{C}), 1299,1215(\nu$, C-N), 1122 ( $\nu, \mathrm{C}-\mathrm{O}), 832,783(\delta, \mathrm{C}-\mathrm{H}), 548,465 .{ }^{\mathbf{1}} \mathbf{H}-\mathbf{N M R}$ $\left(\mathrm{CDCl}_{3}, 500 \mathrm{MHz}, \mathrm{ppm}\right): \delta 7.61(\mathrm{~s}, 2 \mathrm{H}, 2 \mathrm{CH}=\mathrm{N}), 6.98(\mathrm{~d}$, $J=8.5,2 \mathrm{H}, \mathrm{ArH}), 6.67$ (d, $J=2.5,2 \mathrm{H}, \mathrm{ArH}), 6.20$ (dd, $J=8.5$; 2.5, 2H, ArH), 3.79 (s, 6H, 2 MeO), 3.58 (m, 2H, CyH), 2.45 (m, 2H, CyH), 1.85 (m, 2H, CyH), 1.39 (m, 4H, CyH). ${ }^{13} \mathrm{C}-$ NMR $\left(\mathrm{CDCl}_{3}, 125 \mathrm{MHz}, \mathrm{ppm}\right): \delta 165.60$ (2C, C-O), 164.47 (2C, C-OMe), $149.71(2 \mathrm{C}, \mathrm{C}=\mathrm{N}), 134.77\left(2 \mathrm{C}, \mathrm{C}_{\mathrm{Ar}}\right), 116.38$ $\left(2 \mathrm{C}, \mathrm{C}_{\mathrm{Ar}}\right), 106.86\left(2 \mathrm{C}, \mathrm{C}_{\mathrm{Ar}}\right), 103.40\left(2 \mathrm{C}, \mathrm{C}_{\mathrm{Ar}}\right), 73.46(2 \mathrm{C}$, $\left.\mathrm{C}_{\mathrm{Cy}}\right), 55.28(2 \mathrm{C}, 2 \mathrm{MeO}), 27.70\left(2 \mathrm{C}, \mathrm{C}_{\mathrm{Cy}}\right), 24.62\left(2 \mathrm{C}, \mathrm{C}_{\mathrm{Cy}}\right)$.

$[\mathrm{Pt}(S)(\mathrm{L} 4)]$ : yellow precipitate $(70 \%), \mathbf{E S I}-\mathbf{M S}(\mathrm{m} / \mathrm{z})$ $576.0\left(\mathrm{M}+\mathrm{H}^{+}\right),[\boldsymbol{\alpha}]_{\mathbf{D}}+89\left(c\right.$ 0.03; DMSO). IR $\left(\mathrm{KBr}, \mathrm{cm}^{-1}\right)$ : $2935(\nu, \mathrm{C}-\mathrm{H}), 1601(\nu, \mathrm{C}=\mathrm{N}), 1439(\nu, \mathrm{C}=\mathrm{C}), 1299,1215(\nu$, C-N), 1120 ( $\nu, \mathrm{C}-\mathrm{O}), 832,778(\delta, \mathrm{C}-\mathrm{H}), 549,463 .{ }^{\mathbf{1}} \mathbf{H}-\mathbf{N M R}$ $\left(\mathrm{CDCl}_{3}, 500 \mathrm{MHz}, \mathrm{ppm}\right): \delta 7.70(\mathrm{~s}, 2 \mathrm{H}, 2 \mathrm{CH}=\mathrm{N}), 7.05(\mathrm{~d}$, $J=8.5,2 \mathrm{H}, \mathrm{ArH}), 6.70$ (d, $J=2.5,2 \mathrm{H}, \mathrm{ArH}), 6.23$ (dd, $J=9.0$; 2.5, 2H, ArH), 3.79 (s, 6H, 2 MeO), 3.55 (m, 2H, CyH), 2.52 (m, 2H, CyH), 1.89 (m, 2H, CyH), 1.46 (m, 2H, CyH), 1.38 $(\mathrm{m}, 2 \mathrm{H}, \mathrm{CyH}) .{ }^{13} \mathrm{C}-\mathrm{NMR}\left(\mathrm{CDCl}_{3}, 125 \mathrm{MHz}, \mathrm{ppm}\right): \delta 165.72$ (2C, C-O), 164.56 (2C, C-OMe), 149.76 (2C, C=N), 134.71 $\left(2 \mathrm{C}, \mathrm{C}_{\mathrm{Ar}}\right), 116.33\left(2 \mathrm{C}, \mathrm{C}_{\mathrm{Ar}}\right), 107.04\left(2 \mathrm{C}, \mathrm{C}_{\mathrm{Ar}}\right), 103.48(2 \mathrm{C}$, $\left.\mathrm{C}_{\mathrm{Ar}}\right), 73.55\left(2 \mathrm{C}, \mathrm{C}_{\mathrm{Cy}}\right), 55.30(2 \mathrm{C}, 2 \mathrm{MeO}), 27.78\left(2 \mathrm{C}, \mathrm{C}_{\mathrm{Cy}}\right)$, $24.66\left(2 \mathrm{C}, \mathrm{C}_{\mathrm{Cy}}\right)$.

$[\mathrm{Pt}(R)(\mathrm{L} 5)]$ : yellow precipitate (69\%), ESI-MS $(\mathrm{m} / \mathrm{z})$ $576.0\left(\mathrm{M}+\mathrm{H}^{+}\right),[\boldsymbol{\alpha}]_{\mathrm{D}}-186\left(\right.$ c 0.03; DMSO). IR $\left(\mathrm{KBr}, \mathrm{cm}^{-1}\right)$ : $2934(\nu, \mathrm{C}-\mathrm{H}), 1626(\nu, \mathrm{C}=\mathrm{N}), 1476(\nu, \mathrm{C}=\mathrm{C}), 1291,1221(\nu$, C-N), 1160 ( $\nu$, C-O), 833, $788(\delta, \mathrm{C}-\mathrm{H}), 550,452 .{ }^{\mathbf{1}} \mathbf{H}-\mathbf{N M R}$ (DMSO- $\left.d^{6}, 500 \mathrm{MHz}, \mathrm{ppm}\right): \delta 8.41(\mathrm{~s}, 2 \mathrm{H}, 2 \mathrm{CH}=\mathrm{N}), 7.18(\mathrm{~d}$, $J=3.5,2 \mathrm{H}, \operatorname{ArH}), 7.12(\mathrm{dd}, J=9.0 ; 3.0,2 \mathrm{H}, \operatorname{ArH}), 6.82(\mathrm{~d}$, $J=9.0,2 \mathrm{H}, \mathrm{ArH}), 3.70$ (s, 6H, $2 \mathrm{MeO}), 3.53$ (m, 2H, СуH), 2.75 (m, 2H, CyH), 1.81 (m, 2H, CyH), 1.51 (m, 2H, СyH), 1.36 (m, 2H, CyH). ${ }^{13} \mathrm{C}-\mathrm{NMR}$ (DMSO-d $\left.d^{6}, 125 \mathrm{MHz}, \mathrm{ppm}\right)$ : $\delta 158.06(2 \mathrm{C}, \mathrm{C}-\mathrm{O}), 151.26(2 \mathrm{C}, \mathrm{C}=\mathrm{N}), 148.96(2 \mathrm{C}$, C-OMe), $123.03\left(2 \mathrm{C}, \mathrm{C}_{\mathrm{Ar}}\right), 121.01\left(2 \mathrm{C}, \mathrm{C}_{\mathrm{Ar}}\right), 120.42(2 \mathrm{C}$, $\left.\mathrm{C}_{\mathrm{Ar}}\right), 114.74\left(2 \mathrm{C}, \mathrm{C}_{\mathrm{Ar}}\right), 73.40\left(2 \mathrm{C}, \mathrm{C}_{\mathrm{Cy}}\right), 55.50(2 \mathrm{C}, 2 \mathrm{MeO})$, $27.19\left(2 \mathrm{C}, \mathrm{C}_{\mathrm{Cy}}\right), 23.72\left(2 \mathrm{C}, \mathrm{C}_{\mathrm{Cy}}\right)$. 
$[\operatorname{Pt}(S)(\mathrm{L} 5)]$ : yellow precipitate $(71 \%)$, ESI-MS $(\mathrm{m} / \mathrm{z})$ $576.0\left(\mathrm{M}+\mathrm{H}^{+}\right),[\boldsymbol{\alpha}]_{\mathbf{D}}+185\left(\right.$ c 0.03; DMSO). IR $\left(\mathrm{KBr}, \mathrm{cm}^{-1}\right)$ : $2933(\nu, \mathrm{C}-\mathrm{H}), 1627(\nu, \mathrm{C}=\mathrm{N}), 1472(\nu, \mathrm{C}=\mathrm{C}), 1290,1219(\nu$, C-N), 1159 ( $\nu, \mathrm{C}-\mathrm{O}), 833,788(\delta, \mathrm{C}-\mathrm{H}), 550,452 .{ }^{\mathbf{1}} \mathbf{H}-\mathbf{N M R}$ (DMSO- $\left.d^{6}, 500 \mathrm{MHz}, \mathrm{ppm}\right): \delta 8.41(\mathrm{~s}, 2 \mathrm{H}, 2 \mathrm{CH}=\mathrm{N}), 7.18$ (d, $J=3.5,2 \mathrm{H}, \mathrm{ArH}), 7.12(\mathrm{dd}, J=9.0 ; 3.0,2 \mathrm{H}, \mathrm{ArH}), 6.82(\mathrm{~d}$, $J=9.0,2 \mathrm{H}, \mathrm{ArH}), 3.70$ (s, 6H, $2 \mathrm{MeO}), 3.53(\mathrm{~m}, 2 \mathrm{H}, \mathrm{CyH})$, 2.75 (m, 2H, CyH), 1.81 (m, 2H, CyH), 1.51 (m, 2H, CyH), $1.36(\mathrm{~m}, 2 \mathrm{H}, \mathrm{CyH}) .{ }^{13} \mathrm{C}-\mathrm{NMR}$ (DMSO- $\left.d^{6}, 125 \mathrm{MHz}, \mathrm{ppm}\right)$ : $\delta 158.06(2 \mathrm{C}, \mathrm{C}-\mathrm{O}), 151.25(2 \mathrm{C}, \mathrm{C}=\mathrm{N}), 148.96(2 \mathrm{C}$, $\mathrm{C}-\mathrm{OMe}), 123.03\left(2 \mathrm{C}, \mathrm{C}_{\mathrm{Ar}}\right), 121.01\left(2 \mathrm{C}, \mathrm{C}_{\mathrm{Ar}}\right), 120.43(2 \mathrm{C}$, $\left.\mathrm{C}_{\mathrm{Ar}}\right), 114.74\left(2 \mathrm{C}, \mathrm{C}_{\mathrm{Ar}}\right), 73.40\left(2 \mathrm{C}, \mathrm{C}_{\mathrm{Cy}}\right), 55.50(2 \mathrm{C}, 2 \mathrm{MeO})$, $27.18\left(2 \mathrm{C}, \mathrm{C}_{\mathrm{Cy}}\right), 23.72\left(2 \mathrm{C}, \mathrm{C}_{\mathrm{Cy}}\right)$.

$[\operatorname{Pt}(R)(\mathrm{L} 6)]$ : yellow precipitate $(69 \%), \mathbf{E S I}-\mathbf{M S}(\mathrm{m} / \mathrm{z})$ $575.9\left(\mathrm{M}+\mathrm{H}^{+}\right),[\boldsymbol{\alpha}]_{\mathbf{D}}-143\left(c\right.$ 0.03; DMSO). IR $\left(\mathrm{KBr}, \mathrm{cm}^{-1}\right)$ : $2937(\nu, \mathrm{C}-\mathrm{H}), 1602(\nu, \mathrm{C}=\mathrm{N}), 1456(\nu, \mathrm{C}=\mathrm{C}), 1314,1249(\nu$, $\mathrm{C}-\mathrm{N}), 1201,1105(\nu, \mathrm{C}-\mathrm{O}), 1033,859,786(\delta, \mathrm{C}-\mathrm{H}), 530$, 450. ${ }^{1} \mathrm{H}-\mathrm{NMR}$ (DMSO- $\left.d^{6}, 500 \mathrm{MHz}, \mathrm{ppm}\right): \delta 8.65$ (s, 2H, $2 \mathrm{CH}=\mathrm{N}), 7.28(\mathrm{t}, J=8.5,2 \mathrm{H}, \mathrm{ArH}), 6.51(\mathrm{~d}, J=8.5,2 \mathrm{H}, \mathrm{ArH})$, 6.18 (d, $J=7.5,2 \mathrm{H}, \mathrm{ArH}), 3.83$ (s, 6H, $2 \mathrm{MeO}), 3.54(\mathrm{~m}, 2 \mathrm{H}$, $\mathrm{CyH}), 2.63$ (m, 2H, CyH), $1.83(\mathrm{~m}, 2 \mathrm{H}, \mathrm{CyH}), 1.52(\mathrm{~m}, 2 \mathrm{H}$, $\mathrm{CyH}), 1.37$ (m, 2H, CyH). ${ }^{13} \mathrm{C}-\mathbf{N M R}$ (DMSO- $d^{6}, 125 \mathrm{MHz}$, ppm): $\delta 163.40$ (2C, C-O), 159.42 (2C, C-OMe), 145.24 (2C, $\mathrm{C}=\mathrm{N}), 132.38\left(2 \mathrm{C}, \mathrm{C}_{\mathrm{Ar}}\right), 113.81\left(2 \mathrm{C}, \mathrm{C}_{\mathrm{Ar}}\right), 112.14\left(2 \mathrm{C}, \mathrm{C}_{\mathrm{Ar}}\right)$, $96.64\left(2 \mathrm{C}, \mathrm{C}_{\mathrm{Ar}}\right), 73.64\left(2 \mathrm{C}, \mathrm{C}_{\mathrm{Cy}}\right), 55.61(2 \mathrm{C}, 2 \mathrm{MeO}), 27.09$ $\left(2 \mathrm{C}, \mathrm{C}_{\mathrm{Cy}}\right), 23.66\left(2 \mathrm{C}, \mathrm{C}_{\mathrm{Cy}}\right)$.

$[\mathrm{Pt}(S)(\mathrm{L} 6)]$ : yellow precipitate $(68 \%), \mathbf{E S I}-\mathbf{M S}(\mathrm{m} / \mathrm{z})$ $575.9\left(\mathrm{M}+\mathrm{H}^{+}\right),[\boldsymbol{\alpha}]_{\mathrm{D}}+141\left(c \mathrm{0} 03\right.$; DMSO). IR $\left(\mathrm{KBr}, \mathrm{cm}^{-1}\right)$ : $2938(\nu, \mathrm{C}-\mathrm{H}), 1602(\nu, \mathrm{C}=\mathrm{N}), 1456(\nu, \mathrm{C}=\mathrm{C}), 1314,1248(\nu$, C-N), 1201, 1103 ( $\nu, \mathrm{C}-\mathrm{O}), 1033,859,786(\delta, \mathrm{C}-\mathrm{H}), 531$, 450. ${ }^{1} \mathrm{H}-\mathrm{NMR}$ (DMSO- $\left.d^{6}, 500 \mathrm{MHz}, \mathrm{ppm}\right): \delta 8.66(\mathrm{~s}, 2 \mathrm{H}$, $2 \mathrm{CH}=\mathrm{N}), 7.29(\mathrm{t}, J=8.5,2 \mathrm{H}, \mathrm{ArH}), 6.50(\mathrm{~d}, J=8.5,2 \mathrm{H}, \mathrm{ArH})$, 6.20 (d, J=7.5, 2H, ArH), 3.82 (s, 6H, $2 \mathrm{MeO}), 3.53$ (m, 2H, $\mathrm{CyH}), 2.63$ (m, 2H, CyH), $1.81(\mathrm{~m}, 2 \mathrm{H}, \mathrm{CyH}), 1.51(\mathrm{~m}, 2 \mathrm{H}$, $\mathrm{CyH}), 1.34(\mathrm{~m}, 2 \mathrm{H}, \mathrm{CyH}) .{ }^{13} \mathrm{C}-\mathrm{NMR}$ (DMSO-d $d^{6}, 125 \mathrm{MHz}$, ppm): $\delta 163.42$ (2C, C-O), 159.45 (2C, C-OMe), 145.30 (2C, $\mathrm{C}=\mathrm{N}), 132.43\left(2 \mathrm{C}, \mathrm{C}_{\mathrm{Ar}}\right), 113.83\left(2 \mathrm{C}, \mathrm{C}_{\mathrm{Ar}}\right), 112.16\left(2 \mathrm{C}, \mathrm{C}_{\mathrm{Ar}}\right)$, $96.69\left(2 \mathrm{C}, \mathrm{C}_{\mathrm{Ar}}\right), 73.68\left(2 \mathrm{C}, \mathrm{C}_{\mathrm{Cy}}\right), 55.65(2 \mathrm{C}, 2 \mathrm{MeO}), 27.12$ $\left(2 \mathrm{C}, \mathrm{C}_{\mathrm{Cy}}\right), 23.69\left(2 \mathrm{C}, \mathrm{C}_{\mathrm{Cy}}\right)$.

\section{Photophysical Property of Chiral Salen Platinum(II) Complexes}

The UV-visible absorption spectra of the complexes were measured in DCM (dichloromethane) solutions $\left(2 \times 10^{-5} \mathrm{M}\right)$ on Perkin Elmer Lambda UV-35 spectrophotometer. The emission spectra of the solutions were recorded on Horiba Fluorolog spectrofluorometer at room temperature. The obtained photophysical data are shown in Table 1.

\section{In Vitro Cytotoxicity Assay}

Human cancer cells KB and MCF-7 were cultured in DMEM with $10 \%$ fetal bovine serum, $100 \mu \mathrm{g} / \mathrm{mL}$ streptomycin, 100 units/mL penicillin, and $2 \mathrm{mmol} / \mathrm{L} \mathrm{L}$-glutamine at 37으 in humidified atmosphere with $5 \% \mathrm{CO}_{2}$ and $95 \%$ air. Cancer cells were cultivated in 96 well plates for $24 \mathrm{~h}$ followed by treating with different concentrations of complexes in DMSO for $24 \mathrm{~h}$ more. Then, testing cells were exposed to
TABLE 1: Photophysical data of the chiral salen platinum(II) complexes.

\begin{tabular}{lcccc}
\hline Complex & $\pi-\pi^{*}$ & $\begin{array}{c}\lambda_{\text {abs }}(\varepsilon) \\
n-\pi^{*}\end{array}$ & MLCT & $\lambda_{\text {em }}\left(\lambda_{\text {exc }}\right)$ \\
\hline 1R & $317(10,215)$ & $343(12,045)$ & $421(4,635)$ & $546(421)$ \\
1S & $317(8,945)$ & $343(9,770)$ & $421(3,805)$ & $542(421)$ \\
2R & $323(11,870)$ & $351(12,305)$ & $437(5,270)$ & $568(437)$ \\
2S & $323(11.050)$ & $351(11,270)$ & $437(5,105)$ & $566(437)$ \\
3R & $288(13,235)$ & $358(14,375)$ & $434(4,100)$ & $556(434)$ \\
3S & $288(12,685)$ & $358(13,660)$ & $434(4,190)$ & $552(434)$ \\
4R & $314(23,800)$ & $331(25,250)$ & $398(10,080)$ & $531(398)$ \\
4S & $314(22,615)$ & $332(23,850)$ & $398(9,625)$ & $529(398)$ \\
5R & $322(14,230)$ & $360(11,520)$ & $450(6,260)$ & $595(450)$ \\
5S & $322(13,635)$ & $360(10,995)$ & $450(6,015)$ & $593(450)$ \\
6R & $291(14,485)$ & $358(28,020)$ & $424(4,965)$ & $544(423)$ \\
6S & $291(13,345)$ & $358(25,920)$ & $423(4,195)$ & $540(423)$ \\
\hline
\end{tabular}

$10 \mu \mathrm{L}$ of freshly prepared MTT ( $5 \mathrm{mM}$ ) solution and incubated for $2 \mathrm{~h}$ at $37 \underline{\mathrm{oC}}$ in the atmosphere of $5 \% \mathrm{CO}_{2}$. The formazan crystals obtained during MTT incubation were dissolved in $100 \mu \mathrm{L}$ of DMSO. The absorbance was recorded at $540 \mathrm{~nm}$ on Genios TECAN spectrophotometer. The experiments were carried out in triplicates for every concentration of the complexes. The percent viable cells were plotted as a function of concentration to determine the $\mathrm{IC}_{50}$ values presented in Table 2 .

\section{Results and Discussion}

7.1. Synthesis and Characterization. $\mathrm{LH}_{2}$ ligands were formed by the condensation of $\left(R, R^{\prime}\right)$-cyclohexanediamine and $\left(S, S^{\prime}\right)$-cyclohexanediamine with salicylaldehydes (Figure 1), and then the precipitates formed were collected by filtration and washed by cold ethanol in high yields (>90\%). All obtained chiral ligands (Table 3) were characterized by ESI-MS spectra, and the results obtained were in good agreement with those calculated for the suggested formulae. The IR spectra of the Schiff base ligands $\mathrm{LH}_{2}$ revealed typical signals probably presented for new bonding of $\mathrm{CH}=\mathrm{N}$ at $1617-1635 \mathrm{~cm}^{-1}$ and bonding of $\mathrm{O}-\mathrm{H}$ at $2548-2665 \mathrm{~cm}^{-1}, \mathrm{C}-\mathrm{N}$ at $1248-1294 \mathrm{~cm}^{-1}$, and $\mathrm{Ar}-\mathrm{O}$ at $1163-1221 \mathrm{~cm}^{-1}$. On the ${ }^{1} \mathrm{H}-\mathrm{NMR}$ spectra, the singlet proton signals of $\mathrm{CH}=\mathrm{N}$ performed the formation of these Schiff base ligands which were observed at $\delta=8.09-8.68 \mathrm{ppm}$. The ${ }^{1} \mathrm{H}-\mathrm{NMR}$ spectra exhibited proton signals at $1.44-3.32 \mathrm{ppm}$ for $\mathrm{CyHs}$, at $6.19-7.23 \mathrm{ppm}$ for ArHs and at $12.80-14.30 \mathrm{ppm}$ as singlet for OHs. The substituted methoxy groups showed characteristic signals at $3.70-3.86 \mathrm{ppm}$, and fluoro at 5-position of salicyl ring gave the proton signals of aromatic ring in mutiplet as usual. ${ }^{13} \mathrm{C}-\mathrm{NMR}$ spectra exhibited the chemical shifts for carbons of $\mathrm{CH}=\mathrm{N}$ at $\delta=151.61-163.74 \mathrm{ppm}$. The typical signals for carbons of $\mathrm{C}-\mathrm{OH}$ were at $163.71-164.90 \mathrm{ppm}$. The signals at 99.61-133.24 ppm could belong to carbon signals of the salicylidene moiety without substitution. The chemical shifts for carbons with substituted groups moved the higher field compared to the carbon signals without substituted groups, carbons of $\mathrm{C}-\mathrm{OMe}$ at 
Table 2: The cytotoxicity of chiral Pt(II) complexes in vitro.

\begin{tabular}{|c|c|c|}
\hline \multirow{2}{*}{ Complex } & \multicolumn{2}{|c|}{$\mathrm{IC}_{50}(\mu \mathrm{M})$} \\
\hline & $\mathrm{KB}$ & MCF-7 \\
\hline 1R & 12.29 & 10.08 \\
\hline $1 S$ & 11.26 & 7.15 \\
\hline $2 R$ & 29.04 & 27.80 \\
\hline $2 S$ & 22.43 & 8.97 \\
\hline $3 R$ & 22.26 & 9,27 \\
\hline $3 S$ & 21.22 & 8.12 \\
\hline $4 R$ & 30.71 & 29.01 \\
\hline $4 S$ & 13.32 & 10.01 \\
\hline $5 R$ & 13.91 & 15.58 \\
\hline $5 S$ & 10.71 & 7.51 \\
\hline $6 R$ & 10.92 & 7.18 \\
\hline $6 S$ & 10.61 & 5.72 \\
\hline Ellipticine & 1.22 & 2.07 \\
\hline
\end{tabular}

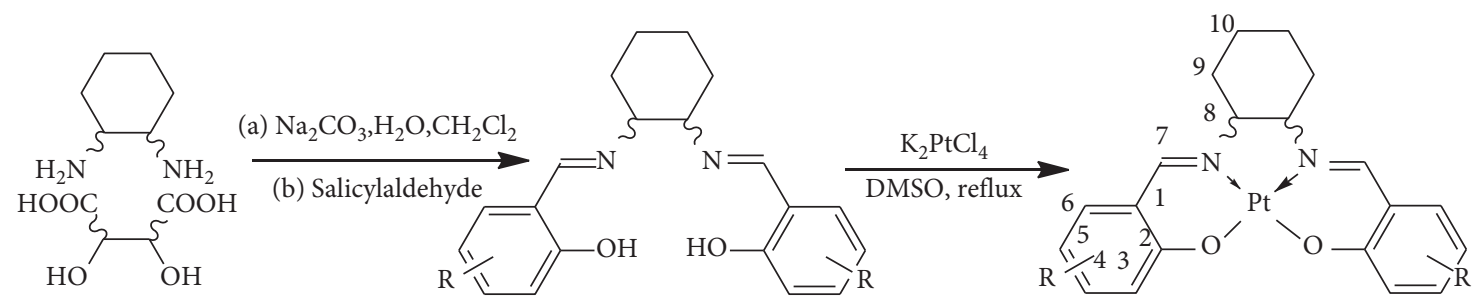

FIgURE 1: Synthesis of chiral salen ligands and Pt(II) complexes.

Table 3: Chiral salen ligands and their Pt(II) complexes.

\begin{tabular}{|c|c|c|}
\hline$R$ & Ligand & Complex \\
\hline $\mathrm{H}$ & $(R) \mathrm{L}_{1} \mathrm{H}_{2}$ & {$[\mathrm{Pt}(R)(\mathrm{L} 1)](\mathbf{1} \mathbf{R})$} \\
\hline $\mathrm{H}$ & $(S) \mathrm{L}_{1} \mathrm{H}_{2}$ & {$[\mathrm{Pt}(S)(\mathrm{L} 1)](\mathbf{1 S})$} \\
\hline $5-\mathrm{F}$ & (R) $\mathrm{L}_{2} \mathrm{H}_{2}$ & {$[\mathrm{Pt}(R)(\mathrm{L} 2)](\mathbf{2} \mathbf{R})$} \\
\hline $5-\mathrm{F}$ & (S) $\mathrm{L}_{2} \mathrm{H}_{2}$ & {$[\mathrm{Pt}(S)(\mathrm{L} 2)](2 \mathrm{~S})$} \\
\hline 3-OMe & $(R) \mathrm{L}_{3} \mathrm{H}_{2}$ & {$[\mathrm{Pt}(R)(\mathrm{L} 3)](3 \mathbf{R})$} \\
\hline 3-OMe & $(S) \mathrm{L}_{3} \mathrm{H}_{2}$ & {$[\mathrm{Pt}(S)(\mathrm{L} 3)](3 \mathrm{~S})$} \\
\hline 4-OMe & $(R) \mathrm{L}_{4} \mathrm{H}_{2}$ & {$[\operatorname{Pt}(R)(\mathrm{L} 4)](4 \mathbf{R})$} \\
\hline 4-OMe & (S) $\mathrm{L}_{4} \mathrm{H}_{2}$ & {$[\mathrm{Pt}(S)(\mathrm{L} 4)](4 \mathrm{~S})$} \\
\hline 5-OMe & $(R) \mathrm{L}_{5} \mathrm{H}_{2}$ & {$[\mathrm{Pt}(R)(\mathrm{L} 5)](\mathbf{5 R})$} \\
\hline 5-OMe & $(S) \mathrm{L}_{5} \mathrm{H}_{2}$ & {$[\mathrm{Pt}(S)(\mathrm{L} 5)](\mathbf{5 S})$} \\
\hline 6-OMe & $(R) \mathrm{L} 6 \mathrm{H}_{2}$ & {$[\operatorname{Pt}(R)(\mathrm{L} 6)](\mathbf{6 R})$} \\
\hline 6-OMe & (S) $\mathrm{L}_{6} \mathrm{H}_{2}$ & {$[\mathrm{Pt}(S)(\mathrm{L} 6)](\mathbf{6 S})$} \\
\hline
\end{tabular}

148.26-163.45 ppm. The chemical shifts for aromatic carbons of salicylidene moiety with fluoro at 5-position exhibited double signals. The chemical shifts for cyclohexane ring carbons were at 24.05-72.76 ppm, and for $\mathrm{MeO}$ groups, they were about 55.29-56.04 ppm.

$\mathrm{Pt}(\mathrm{II})$ complexes in the list (Table 3 ) were obtained in moderate yields (67-73\%) by the reaction of $\mathrm{K}_{2} \mathrm{PtCl}_{4}$ with each ligand in DMSO. The complexes were characterized by ESI-MS, IR, and NMR. The results received by ESI-MS were suitable to the suggested formulae (Figure 1). The IR spectra of obtained complexes showed the typical signals at $1601-1627 \mathrm{~cm}^{-1}$ for $\mathrm{C}=\mathrm{N}, 1190-1248$ for $\mathrm{C}-\mathrm{N}$, and $1103-1159 \mathrm{~cm}^{-1}$ for $\mathrm{Ar}-\mathrm{O}$ bonding stretching vibrations. There was no signal for $\mathrm{O}-\mathrm{H}$ bonding in the complexes, and there were signals for $\mathrm{Pt}-\mathrm{N}$ and $\mathrm{Pt}-\mathrm{O}$ of new bonding stretching vibrations at $531-571 \mathrm{~cm}^{-1}$ and $450-472 \mathrm{~cm}^{-1}$, respectively, conforming that the $\mathrm{Pt}(\mathrm{II})$ complexes were coordinated. The ${ }^{1} \mathrm{H}-\mathrm{NMR}$ spectra revealed the proton signals of $\mathrm{CH}=\mathrm{N}$ at $\delta=7.62-8.66 \mathrm{ppm}$, ArHs at $6.10-7.48 \mathrm{ppm}$, and $\mathrm{CyHs}$ at $1.33-3.70 \mathrm{ppm}$. The substituted methoxy groups showed characteristic signals at 3.70-3.82 ppm and aromatic proton signals with fluoro at 5position salicyl ring were shown in mutiplet. ${ }^{13} \mathrm{C}-\mathrm{NMR}$ spectra exhibited the typical signals at $154.20-164.65 \mathrm{ppm}$ for carbons of C-O and 145.30-151.64 ppm for carbons of $\mathrm{CH}=\mathrm{N}$. The carbon signals of salicylidene moiety could be at 96.69-134.94 ppm, and for cyclohexane ring, they were at 23.63-73.71 ppm. The aromatic carbon signals linking the substituted groups must be exhibited at 153.36 and $151.51 \mathrm{ppm}$ for $\mathrm{C}-\mathrm{F}$ and $148.96-163.74 \mathrm{ppm}$ for C-OMe. The carbon signals of the substituted methoxy groups could be shown at 54.59-55.65 ppm.

It was similar to IR spectra, and there were no big different signals on ${ }^{1} \mathrm{H}$ and ${ }^{13} \mathrm{C}$-NMR spectra of $(R)$ - and $(S)$ enantiomers of ligands and platinum(II) complexes except opposite rotations of polarized light. The CD spectra of these couples of enantiomeric $\mathrm{Pt}(\mathrm{II})$ complexes in methanol or $\operatorname{DCM}(4 R, 4 S$ and $6 R, 6 S)$ were measured at room temperature from 235 to $400 \mathrm{~nm}$. The couples of chiral enantiomers emitted the equal intense peaks with the opposite orientation (Figure 2), respectively, which demonstrated the existence of the chiral enantiomers.

7.2. Photophysical Property of Chiral Salen Platinum(II) Complexes. The photophysical data are shown in Table 1. When dissolved in DCM, all complexes afforded the yellow 


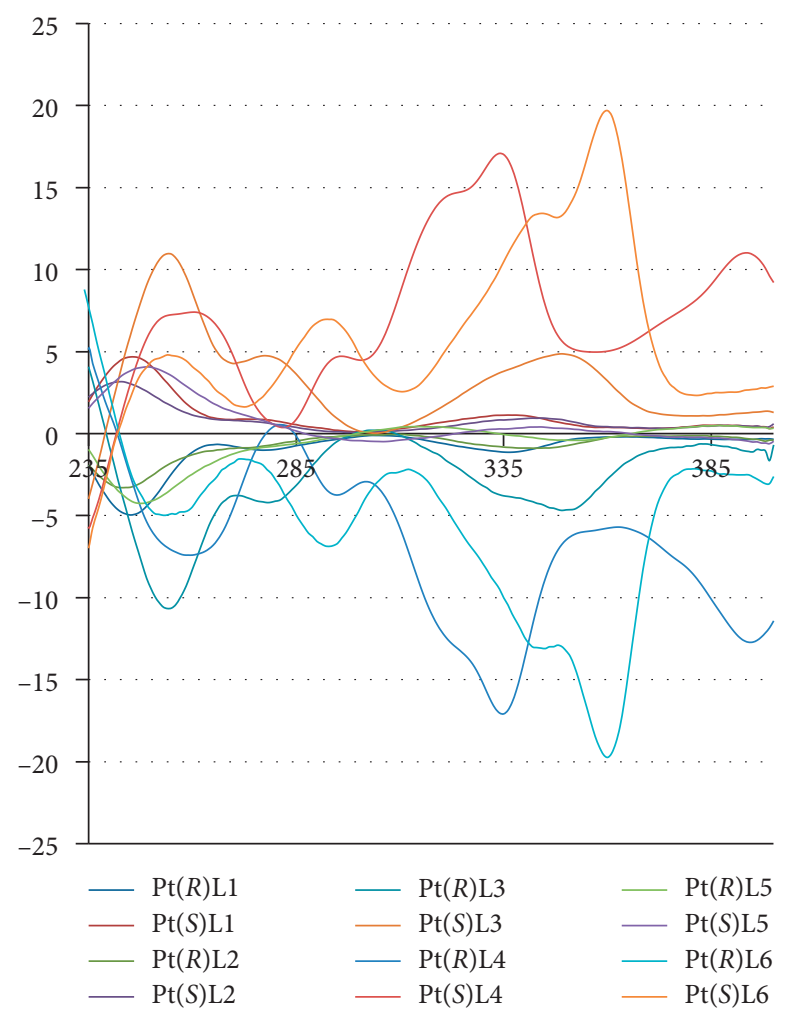

Figure 2: CD spectra of chiral salen Pt(II) complexes.

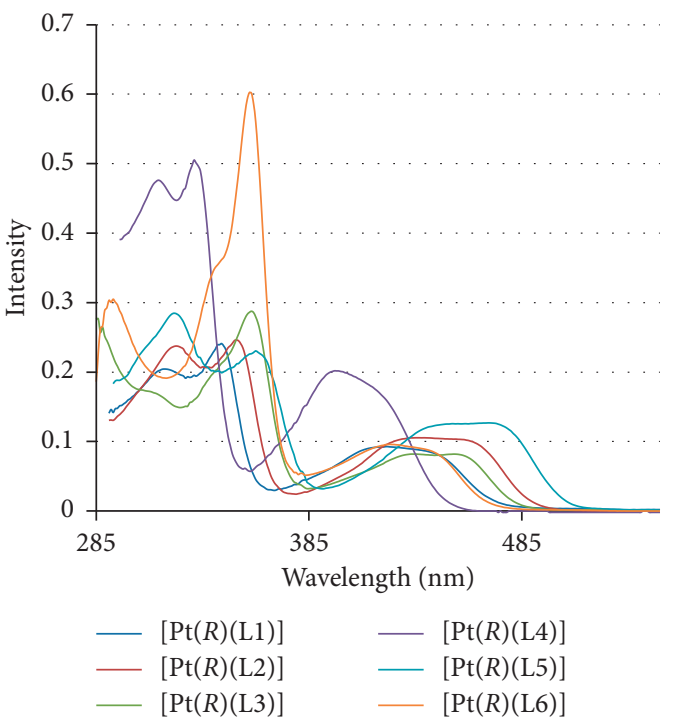

(a)

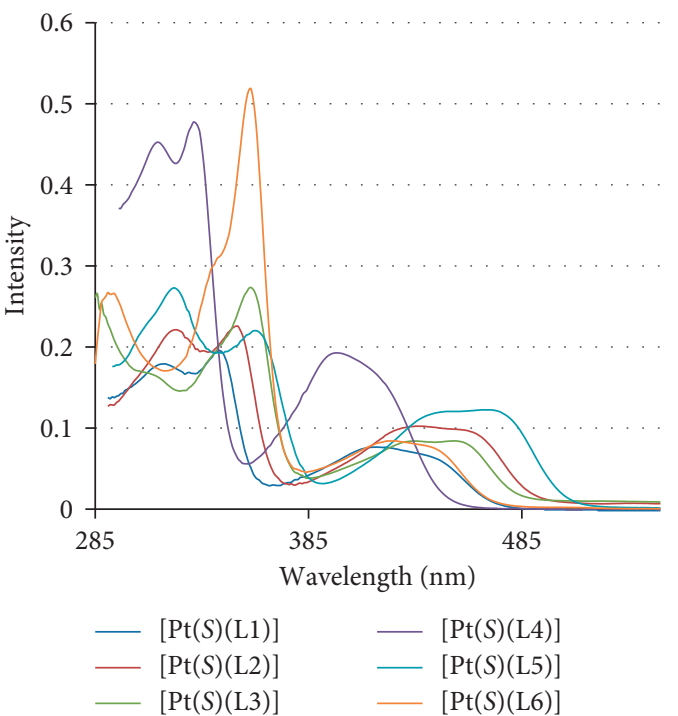

(b)

Figure 3: UV-visible spectra of chiral salen Pt(II) complexes.

solution and exhibited UV-Vis absorption and emission spectra.

There were three main absorption bands as usual on UVVis spectra, two intense absorption bands at $288-323 \mathrm{~nm}$ and $331-360 \mathrm{~nm}$ are probably attributed to intraligand absorption, and the visible band at 398-450 $\mathrm{nm}$ may belong to the MLCT (metal-to-ligand charge transfer) state due to $\operatorname{Pt}(5 \mathrm{~d}) \longrightarrow \pi^{*}$ transition (Figure 3 ). There were no meaningful difference in $\lambda_{\max (a b s)}$ between enantiomeric $\mathrm{Pt}(\mathrm{II})$ complexes in $(R)$ and $(S)$ configuration. The luminescence spectra from the corresponding excited state possessed an emission maximum at $529-595 \mathrm{~nm}$. The emission maximum wavelengths of complexes' (S)-enantiomers were similar to $(R)$-enantiomers (Table 1). The Pt(II) complexes with substituted groups at aromatic ring C5position show emission peaks at $566-595 \mathrm{~nm}$, red-shifted 


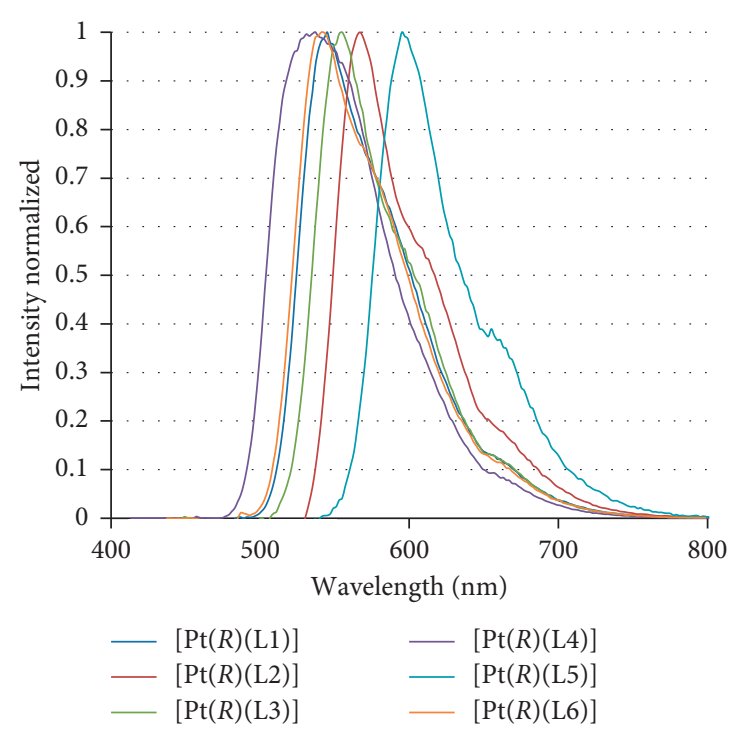

(a)

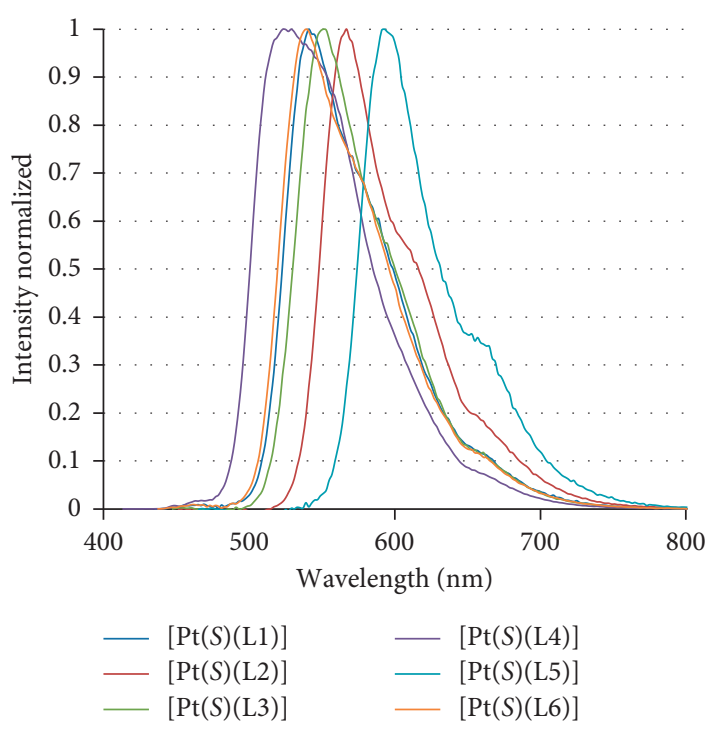

(b)

FIgUre 4: Emission spectra of chiral salen $\mathrm{Pt}(\mathrm{II})$ complexes.

from ca. $542 \mathrm{~nm}$. The complexes with $\mathrm{MeO}$ groups at different positions exhibited different emission wavelengths; the substituted group which occurred at $\mathrm{C} 4$ and $\mathrm{C} 6$ position of salicylidene moiety of the complexes shifted emission peaks to blue range while the group at $\mathrm{C} 3$ and $\mathrm{C} 5$ position shifted those to red region (Figure 4). $\mathrm{MeO}$ groups at $\mathrm{C} 3$ and $\mathrm{C} 5$ had ortho- and para-effect to the bond $\mathrm{C}-\mathrm{O}$, so they may make the band gap HOMO-LUMO of the bond O-Pt to be narrower. $\mathrm{MeO}$ groups at $\mathrm{C} 4$ and $\mathrm{C} 6$ had meta-effect to the bond $\mathrm{C}-\mathrm{O}$, so they may make the band gap HOMO-LUMO of the bond $\mathrm{O}-\mathrm{Pt}$ to be bigger.

7.3. In Vitro Cytotoxicity Assay. In order to estimate possible effect of ligand enantiomers and substituted groups to the platinum(II) complexes' antitumor activity, the in vitro cytotoxicity of the studied $\mathrm{Pt}(\mathrm{II})$ complexes was validated against two human cancer cell lines of KB and MCF-7. The cytotoxicity of ellipticine, a standard anticancer compound, was also evaluated in the same condition for comparison. The $\mathrm{IC}_{50}$ values (the concentration that inhibited in 50\% cellular proliferation) of the obtained complexes are presented in Table 2.

It was noted that all complexes exhibited the antitumor effect with low $\mathrm{IC}_{50}$ value $(<50 \mu \mathrm{M})$ for $\mathrm{KB}$ and MCF-7 human cancer cell lines. In particular, complexes 1S, 5S, 6R, and $6 \mathrm{~S}$ had good anticancer activity for both KB and MCF-7 human cancer cell lines. Enantiomers in $(S)$ configuration gave more effect for the Pt(II) complexes' cytotoxicity than ones in $(R)$ configuration (Table 2). The obtained results were similar to the previous results of chiral $\mathrm{Ru}(\mathrm{II})$ and $\mathrm{Mn}$ (III) salen complexes because the DNA binding affinity of chiral salen complexes $(S)$ - would be greater than $(R)$ $[25,26]$. The complexes 3-6 with different methoxy group positions on salicyl ring had different activities. The introduction of methoxy groups to salicylidene moiety afforded the complex $\mathbf{6 S}$ with the best antitumor activity obviously for
KB and MCF-7 human cancer cells. The complex $\mathbf{6 S}$ had the anticancer activity for MCF-7 human cancer cells with $\mathrm{IC}_{50}$ of $5.72 \mu \mathrm{M}$ which was quite close to $\mathrm{IC}_{50}$ of the standard compound ellipticine $(2.07 \mu \mathrm{M})$.

\section{Conclusions}

In this research, a series of platinum(II) complexes with chiral tetradentate salen ligands were synthesized from salicylaldehydes and $\left(R, R^{\prime}\right)$-cyclohenxanediamine and $\left(S, S^{\prime}\right)$-cyclohenxanediamine and characterized by IR, ESIMS, NMR, and CD spectra. Photophysical properties showed their typical absorption and luminescence in UVvisible region. The luminescent spectra exhibited the effect of substituted groups to their luminescent wavelengths obviously; however, there was no big difference between enantiomeric complexes in $(R)$ and $(S)$ configuration. Complex 5 with the substituted $\mathrm{MeO}$ at $\mathrm{C} 5$-position of salicylidene moiety gave farthest red-shift luminescence (at $595 \mathrm{~nm}$ ). The in vitro antitumor activity of the studied complexes have been evaluated against KB and MCF-7 human cancer cells by MTT assay, and the results showed all complexes had activity against tested human cancer cell lines. The antitumor activity of enantiomers in $(S)$ configuration was more favourable than enantiomers in $(R)$ configuration. The complexes $6 \mathrm{~S}$ were the most effective agents to $\mathrm{KB}$ and MCF-7 human cancer cells, respectively.

\section{Data Availability}

All data used to support the findings of this study are included within the article.

\section{Conflicts of Interest}

The authors declare that there are no conflicts of interest regarding the publication of this paper. 


\section{Acknowledgments}

This study was financially supported by the Vietnam Academy of Science and Technology under grant no. VAST04.01/17-18.

\section{Supplementary Materials}

This section includes the spectral data of synthetic chiral ligands and Pt(II) complexes. These data include ESI-MS, IR, ${ }^{1} \mathrm{H}-\mathrm{NMR}$, and ${ }^{13} \mathrm{H}$-NMR spectra of the synthesized chiral ligands $(R) \mathrm{L}_{1} \mathrm{H}_{2}$ and $(S) \mathrm{L}_{1} \mathrm{H}_{2},(R) \mathrm{L}_{2} \mathrm{H}_{2}$ and $(S) \mathrm{L}_{2} \mathrm{H}_{2},(R)$ $\mathrm{L}_{3} \mathrm{H}_{2}$ and $(S) \mathrm{L}_{3} \mathrm{H}_{2},(R) \mathrm{L}_{4} \mathrm{H}_{2}$ and $(S) \mathrm{L}_{4} \mathrm{H}_{2},(R) \mathrm{L} \mathrm{H}_{2}$ and $(S)$

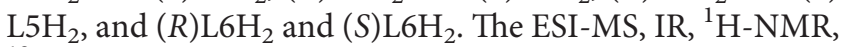
${ }^{13} \mathrm{C}$-NMR, and CD spectra of obtained $\mathrm{Pt}(\mathrm{II})$ complexes $[\mathrm{Pt}(R)(\mathrm{L} 1)]$ and $[\mathrm{Pt}(S)(\mathrm{L} 1)],[\mathrm{Pt}(R)(\mathrm{L} 2)]$ and $[\mathrm{Pt}(S)(\mathrm{L} 2)]$, $[\mathrm{Pt}(R)(\mathrm{L} 3)]$ and $[\mathrm{Pt}(S)(\mathrm{L} 3)],[\operatorname{Pt}(R)(\mathrm{L} 4)]$ and $[\mathrm{Pt}(S)(\mathrm{L} 4)]$, $[\mathrm{Pt}(R)(\mathrm{L} 5)]$ and $[\mathrm{Pt}(S)(\mathrm{L} 5)]$, and $[\mathrm{Pt}(R)(\mathrm{L} 6)]$ and $[\mathrm{Pt}(S)(\mathrm{L} 6)]$ are also provided. (Supplementary Materials)

\section{References}

[1] C. M. da Silva, D. L. da Silva, L. V. Modolo et al., "Schiff bases: a short review of their antimicrobial activities," Journal of Advanced Research, vol. 2, no. 1, pp. 1-8, 2011.

[2] K. C. Gupta and A. K. Sutar, "Catalytic activities of Schiff base transition metal complexes," Coordination Chemistry Reviews, vol. 252, no. 12-14, pp. 1420-1450, 2008.

[3] X. Liu, C. Manzur, N. Novoa, S. Celedón, D. Carrillo, and J.-R. Hamon, "Multidentate unsymmetrically-substituted Schiff bases and their metal complexes: synthesis, functional materials properties, and applications to catalysis," Coordination Chemistry Reviews, vol. 357, pp. 144-172, 2018.

[4] X. Jin, J. Ding, Q. Xia et al., "Catalytic conversion of $\mathrm{CO}_{2}$ and shale gas-derived substrates into saturated carbonates and derivatives: catalyst design, perf ormances and reaction mechanism," Journal of $\mathrm{CO}_{2}$ Utilization, vol. 34, pp. 115-148, 2019.

[5] W. A. Zoubi and N. A. Mohanna, "Membrane sensors based on Schiff bases as chelating ionophores-a review," Spectrochimica Acta Part A: Molecular. Biomolecular. Spectroscopy, vol. 132, pp. 854-870, 2014.

[6] N.-F. Mazlan, L. L. Tan, N. H. A. Karim, L. Y. Heng, and M. I. H. Reza, "Optical biosensing using newly synthesized metal salphen complexes: a potential DNA diagnostic tool," Sensors and Actuators B: Chemical, vol. 242, pp. 176-188, 2017.

[7] D. Çakmak, S. Çakran, S. Yalçinkaya, and C. Demetgül, "Synthesis of salen-type Schiff base metal complexes, electropolymerization on graphite electrode surface and investigation of electrocatalytic effects," Journal of Electroanalytical Chemistry, vol. 808, no. 1, pp. 65-74, 2018.

[8] J. Zhang, L. Xu, and W.-Y. Wong, "Energy materials based on metal Schiff base complexes," Coordination Chemistry Reviews, vol. 355, pp. 180-198, 2018.

[9] J. Zhang, G. Dai, F. Wu et al., "Efficient and tunable phosphorescence of new platinum(II) complexes based on the donor- $\pi$-acceptor Schiff bases," Journal of Photochemistry and Photobiology A: Chemistry, vol. 316, pp. 12-18, 2016.

[10] Y. Zhang, F. Meng, C. You et al., "Achieving NIR emission for tetradentate platinum(II) salophen complexes by attaching dual donor-accepter frameworks in the heads of salophen," Dyes and Pigments, vol. 138, pp. 100-106, 2017.
[11] A. Erxleben, "Transition metal salen complexes in bioinorganic and medicinal chemistry," Inorganica Chimica Acta, vol. 472, pp. 40-57, 2018.

[12] A. M. Abu-Dief and I. M. A. Mohamed, "A review on versatile applications of transition metal complexes incorporating Schiff bases," Beni-Suef University Journal of Basic and Applied Sciences, vol. 4, no. 2, pp. 119-133, 2015.

[13] S. C. Manna, S. Mistri, A. Patra et al., "Synthesis, structure, DNA/protein binding, molecular docking and in vitro anticancer activity of two Schiff base coordinated copper(II) complexes," Polyhedron, vol. 171, pp. 77-85, 2019.

[14] H. Shi, G. J. Clarkson, and P. J. Sadler, "Dual action photosensitive platinum(II) anticancer prodrugs with photoreleasable azide ligands," Inorganica Chimica Acta, vol. 489, pp. 230-235, 2019.

[15] H. Bahron, S. S. Khaidir, A. M. Tajuddin, K. Ramasamy, and B. M. Yamin, "Synthesis, characterization and anticancer activity of mono- and dinuclear $\mathrm{Ni}(\mathrm{II})$ and $\mathrm{Co}(\mathrm{II})$ complexes of a Schiff base derived from o-vanillin," Polyhedron, vol. 161, pp. 84-92, 2019.

[16] S. Sharma, M. Chauhan, A. Jamsheera, S. Tabassum, and F. Arjmand, "Chiral transition metal complexes: synthetic approach and biological applications," Inorganica Chimica Acta, vol. 458, pp. 8-27, 2017.

[17] N.-u. H. Khan, N. Pandya, K. J. Prathap et al., "Chiral discrimination asserted by enantiomers of $\mathrm{Ni}(\mathrm{II}), \mathrm{Cu}(\mathrm{II})$ and $\mathrm{Zn}$ (II) Schiff base complexes in DNA binding, antioxidant and antibacterial activities," Spectrochimica Acta Part A: Molecular and Biomolecular Spectroscopy, vol. 81, no. 1, pp. 199-208, 2011.

[18] X.-Q. Zhou, Y. Li, D.-Y. Zhang et al., "Copper complexes based on chiral Schiff-base ligands: DNA/BSA binding ability, DNA cleavage activity, cytotoxicity and mechanism of apoptosis," European Journal of Medicinal Chemistry, vol. 114, pp. 244-256, 2016.

[19] Z. Li, M. Niu, G. Chang, and C. Zhao, "Chiral manganese (IV) complexes derived from Schiff base ligands: synthesis, characterization, in vitro cytotoxicity and DNA/BSA interaction," Journal of Photochemistry and Photobiology B: Biology, vol. 153, pp. 473-482, 2015.

[20] M. Proetto, W. Liu, A. Hagenbach, U. Abram, and R. Gust, "Synthesis, characterization and in vitro antitumour activity of a series of novel platinum(II) complexes bearing Schiff base ligands," European Journal of Medicinal Chemistry, vol. 53, pp. 168-175, 2012.

[21] M. Azam, S. I. Al-Resayes, S. M. Soliman, A. TrzesowskaKruszynska, R. Kruszynski, and Z. Khan, "A (salicylaldiminato)Pt(II) complex with dimethylpropylene linkage: synthesis, structural characterization and antineoplastic activity," Journal of Photochemistry and Photobiology B: Biology, vol. 176, pp. 150-156, 2017.

[22] S. Banerjee, M. Capper, G. J. Clarkson, H. Huang, and P. J. Sadler, "Dual-action platinum(II) Schiff base complexes: photocytotoxicity and cellular imaging," Polyhedron, vol. 172, pp. 157-166, 2019.

[23] Q. T. Nguyen, Q. H. Lam, P. N. Pham Thi, and V. T. Nguyen, "Synthesis, characterization and in vitro cytotoxicity of platinum(II) complexes with some tetradentate salen ligands," Science Journal Chemistry, vol. 7, no. 2, pp. 49-55, 2019.

[24] H. Naeimi, J. Safari, and A. Heidarnezhad, "Synthesis of Schiff base ligands derived from condensation of salicylaldehyde derivatives and synthetic diamine," Dyes and Pigments, vol. 73, no. 2, pp. 251-253, 2007. 
[25] N.-u. H. Khan, N. Pandya, R. I. Kureshy et al., "Synthesis, characterization, DNA binding and cleavage studies of chiral $\mathrm{Ru}(\mathrm{II})$ salen complexes," Spectrochimica Acta Part A: Molecular and Biomolecular Spectroscopy, vol. 74, no. 1, pp. 113-119, 2009.

[26] N. H. Khan, N. Pandya, M. Kumar et al., "Influence of chirality using $\mathrm{Mn}$ (III) salen complexes on DNA binding and antioxidant activity," Organic \& Biomolecular Chemistry, vol. 8, pp. 4297-4307, 2009. 